\title{
AVALIAÇÃO DE MODELOS MATEMÁTICOS DESENVOLVIDOS PARA AUXILIAR A TOMADA DE DECISÃO EM SISTEMAS DE PRODUÇÃO DE RUMINANTES EM PASTAGENS
}

\section{HENRIQUE ROCHA DE MEDEIROS}

\author{
Médico Veterinário
}

\begin{abstract}
Tese apresentada à Escola Superior de Agricultura "Luiz de Queiroz", Universidade de São Paulo, para obtenção do título de Doutor em Agronomia, Área de Concentração: Ciência Animal e Pastagens.
\end{abstract}

P I R A C I C A B A

Estado de São Paulo - Brasil

Agosto - 2003 


\title{
AVALIAÇÃO DE MODELOS MATEMÁTICOS DESENVOLVIDOS PARA AUXILIAR A TOMADA DE DECISÃO EM SISTEMAS DE PRODUÇÃO DE RUMINANTES EM PASTAGENS
}

\section{HENRIQUE ROCHA DE MEDEIROS}

\author{
Médico Veterinário
}

Orientador: Prof. Dr. CARLOS GUILHERME SILVEIRA PEDREIRA

\footnotetext{
Tese apresentada à Escola Superior de Agricultura "Luiz de Queiroz", Universidade de São Paulo, para obtenção do título de Doutor em Agronomia, Área de Concentração: Ciência Animal e Pastagens.
}

P I R A C I C A B A

Estado de São Paulo - Brasil

Agosto - 2003 
Dados Internacionais de Catalogação na Publicação (CIP) DIVISÃO DE BIBLIOTECA E DOCUMENTAÇÃO - ESALQ/USP

\section{Medeiros, Henrique Rocha de}

Avalia ção de modelos ma temátic os desenvolvidos pa ra auxiliar a tomada de decisão em sistemas de produção de ruminantesem pastagens / Henrique Rocha de Medeiros. - - Piracicaba, 2003.

$98 \mathrm{p}$.

Tese (doutorado) - Escola Superior de Agric ultura Luiz de Queiroz, 2003. Bibliografia.

1. Capim Tifton 2. Climatologia 3. Consumo 4. Imigação 5. Pastagens 6. Produção vegetal I. Título 


\section{AGRADECIMENTOS}

A DEUS, por guiar o meu caminho e conceder a felicidade de uma família unida, que sempre incentivou e apoiou o sonho de estudar.

Ao Professor CARLOS G. S. PEDREIRA, pela orientação, respeito, amizade e incentivar sempre a superar as dificuldades surgidas no decorrer do trabalho como uma lição positiva.

Ao meu amigo ALEXANDRE MELLO, pelo incentivo e apoio dado à realização deste trabalho, mesmo quando este ainda era uma idéia.

Aos Drs. LUIZ BARIONI e SIMON WOODWARD, pelo incentivo, ensinamentos e suporte dado a este trabalho da elaboração do projeto até sua conclusão.

Ao Professor NILSON VILLA NOVA, pelo exemplo de simplicidade, de alegria, ajuda e sugestões durante todo o doutorado.

A todos os professores e funcionários da ESALQ, que contribuíram para a realização deste trabalho.

Aos professores JOHN HODGSON, STEVE MORRIS, DOUG STIRLING e CORY MATHEWS pelo apoio e orientação recebidos durante o estágio realizado na Massey University da Nova Zelândia. 
A GIOVANNA BONI e família pelo carinho recebido durante a minha estadia em Piracicaba.

Aos amigos MICHELLE COSTA, DANIELE LOURES, RAUL SANTIN, LUCIANA GERDES, RENATO ROVERATTI, SÉRGIO FERNANDES, SORAIA MATARAZZO, LUCY L. PEREIRA, FRANCISCO CABRAL e famílias pela agradável convivência, incentivo e apoio durante todo o Doutorado.

Aos meus colegas, JOAO MENEZES, LEONARDO MORENO e ANDRÉ SBRISSIA, CLAUDIO MACHADO e ALVARO ROMERA pelas sugestões e contribuições durante a elaboração deste trabalho.

A todos os colegas de curso, pela convivência alegre, constante troca de experiências e conhecimento.

A NATÁLIA BENQUET, ALEXANDRA AYUME, JUAN e PATRÍCIA CONTRERAS, PATRÍCIA SALLES, JOSÉ MARIA, JOHN ALLAWANEH e todos que fazem parte da LASA ( Latin American Students Association), pelo apoio e amizade durante o período na Massey University.

Aos amigos ALEYSSON O. PAZA, ALESSANDRO C. DA SILVA pela receptividade na minha chegada Piracicaba.

Ao meu amigo ALBANY SALUSTINO FERNANDES DUTRA, testemunha e exemplo de que as dificuldades podem são superadas com fé em Deus e união da família.

Aos professores da Universidade Federal Rural Pernambuco por terem me incentivado àrealização do Doutorado. 
À Fundação de Amparo a Pesquisa do Estado de São Paulo - FAPESP, pela concessão da bolsa de estudos e o financiamento deste projeto de pesquisa.

A todos os meus professores desde "tia" LUCIMAR (a primeira que me recordo) e "tia" GRACINHA ( que me ensinou as primeiras letras) ao "tio" PEDREIRA (meu orientador e cuja disciplina foi a última que cursei oficialmente na ESALQ), seus ensinamentos me ajudaram crescer e escrever este trabalho. 


\section{SUMÁRIO}

Página

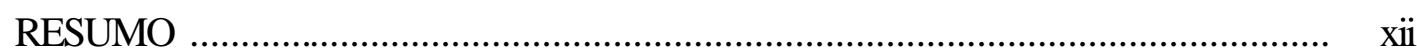

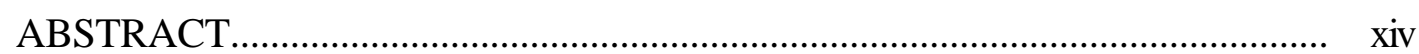

$1 \quad$ INTRODUÇÃO …….......................................................... 2

2 REVISÃO DE LITERATURURA ............................................................ 4

2.1 Conceitos de Sistemas e modelos matemáticos ........................................... 4

2.2 Modelagem matemática da dinâmica da pastagem .................................... 15

2.3 Considerações finais............................................................................. 25

3 AVALIAÇÃO DO MODELO STOCKPOL NOS SISTEMAS DE 26 PECUÁRIA DE CORTE BRASILEIRO

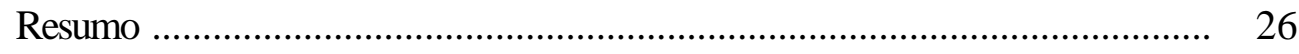

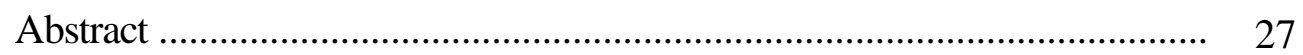

3.1 Introdução ................................................................................ 28

3.2 Material e métodos ............................................................................ $\quad 30$

3.2.1 Descrição do modelo ............................................................................ $\quad 30$

3.2.2 Organização dos bancos de dados .............................................................. 34

3.3.3 Descrição do cenário simulado ................................................................. 35

3.3.4 Análise estatística ............................................................................ 36

3.4 Resultados e discussão ....................................................................... 37

3.5 Conclusões ........................................................................ 43

4 VALIDAÇÃO DE UM MODELO MATEMÁTICO PARA ESTIMAR O 45

ACÚMULO DE FORRAGEM EM FUNÇÃO DE VARIÁVEIS

CLIMÁTICAS

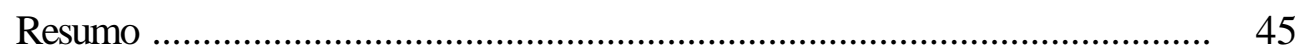

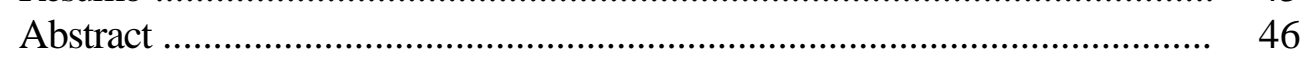

$4.1 \quad$ Introdução ................................................................................ 47

4.2 Material e métodos ................................................................................. 48

4.2.1 Calculo da unidade Fototérmica ............................................................. 48

4.2.2 Dados utilizados na validação do modelo .................................................. 50

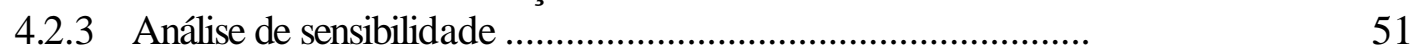

4.2.4 Análise estatística ............................................................................... 52 
$4.3 \quad$ Resultados e discussão ...................................................................... 53

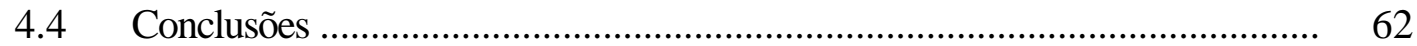

5 AVALIAÇÃO DE MODELOS MATEMÁTICOS PARA ESTIMAR O 63 CONSUMO DE FORRAGEM E O DESEMPENHO ANIMAL EM PASTAGENS

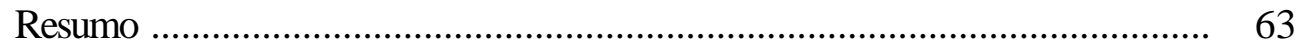

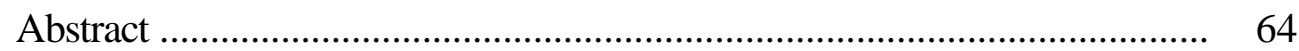

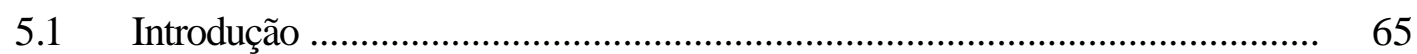

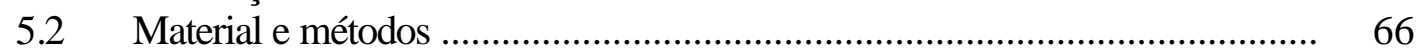

5.21 Descrição dos modelos utilizados .............................................................. 66

5.2.2 Descriçãão do cenário simulado .................................................................... $\quad 70$

5.2.3 Análise estatística ................................................................................. 73

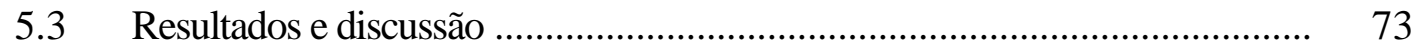

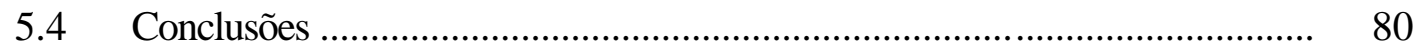

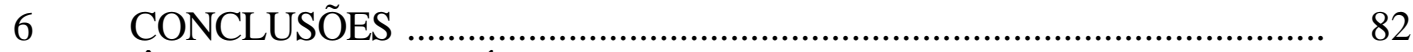

REFERÊNCIAS BIBLIOGRÁFICAS ………........................................... 85 


\title{
AVALIAÇÃo DE MODELOS MATEMÁTICOS DESENVOLVIDOS PARA AUXILIAR A TOMADA DE DECISÃO EM SISTEMAS DE PRODUÇÃO DE RUMINANTES EM PASTAGENS
}

\author{
Autor: HENRIQUE ROCHA DE MEDEIROS \\ Orientador: Prof. Dr. CARLOS GUILHERME SILVEIRA PEDREIRA
}

\section{RESUMO}

Nos sistemas agropecuários (SA) o meio-ambiente, o solo, os animais e as plantas são componentes indissociáveis no processo de produção. Além disso, nesses sistemas o tempo de produção é relativamente longo. Essas características dos SA incrementam o risco e a incerteza associados às alternativas de decisão tomadas no processo de produção. Uma ferramenta que pode ser utilizada para auxiliar esse processo são os modelos matemáticos. Os modelos são uma representação simplificada da realidade e permitem estimar a resposta (e.g., produção) de um sistema face a alterações no processo e/ou descrever e compreender alguns dos processos que ocorrem dentro deste. Este trabalho teve como objetivos (i) testar o modelo Stockpol ${ }^{\circledR}$ nas condições e sistemas 
de produção de ruminantes em pastagens brasileiros, (ii) validar um modelo de acúmulo de forragem em função de variáveis climáticas, e (iii) avaliar modelos para estimar consumo de forragem em sistemas de produção de ruminantes em pastagens. Para esse propósito foram identificadas publicações com informações suficientes que pudessem ser utilizadas nos exercícios de validação e avaliação modelos testados. As informações selecionadas sobre os sistemas de produção utilizados no Brasil foram catalogadas em três bancos de dados: pastagens, bovinos e indicadores de preços e insumos. Esse trabalho de organização dos bancos de dados permitiu identificar áreas carentes de pesquisa (como, por exemplo, a estacionalidade de produção forrageira e consumo de forragem por animais em pastejo) além da necessidade de se padronizar os procedimentos metodológicos, para que se possa comparar e integrar os resultados obtidos diversas regiões do Brasil. Apesar das limitações encontradas, se forem realizados ajustes nos parâmetros e/ou a inclusão de novas variáveis no modelo Stockpol $^{\circledR}$, esse poderá vir a ser uma ferramenta de auxílio à pesquisa e ao processo de tomada de decisão nos sistemas de produção de ruminantes em pastagens do Brasil. O Modelo de Unidades Fototérmicas (UF) proposto é adequado para estimar a produção de Cynodon spp. desde que os fatores de variação sejam unicamente fotoperíodo e temperatura. Nesse modelo as simulações deverão ser realizadas para períodos entre $28 \mathrm{e}$ 42 dias, e a temperatura base utilizada entre 13 e $15^{\circ} \mathrm{C}$. No futuro, mais variáveis (e. g. balanço hídrico) poderão ser incorporadas ao modelo a fim de melhorar a exatidão das suas estimativas. O modelo avaliado para estimar consumo de forragem por ruminantes em pastejo deverá ser reparametrizado e/ou utilizar a oferta de folhas (massa de folhas verdes dividida pelo peso vivo animal, ambos numa mesma área de pastagem), quando 
aplicado a sistemas que utilizem pastagens de clima tropical. O modelo para estimar desempenho não estimou corretamente o ganho de peso dos animais, provavelmente devido à superestimativa do custo energético do pastejo e/ou da subestimativa do valor nutritivo da dieta selecionada pelos animais. Espera-se que solucionado essa questão, o modelo de desempenho animal possa trabalhar em conjunto com os modelos de UF e de consumo de forragem para que assim seja possível realizar simulações de um sistema de produção de ruminantes nas condições climáticas brasileiras e com pastagens de clima tropical. 


\title{
EVALUATION OF MATHEMATICAL MODELS DEVELOPED TO AID DECISION-MAKING IN PASTURE-BASED RUMINANT PRODUCTION SYSTEMS
}

\author{
Author: HENRIQUE ROCHA DE MEDEIROS \\ Adviser: Prof. Dr. CARLOS GUILHERME SILVEIRA PEDREIRA
}

\section{SUMMARY}

In agricultural systems, environment, soil, animals and plants are indissociable components of the production process. Furthermore, the production time-frame is relatively long. These characteristics enhance risk and uncertainty associated with decision alternatives made during the process. One tool which can aid in decisionmaking in these processes is the use of mathematical modeling. Models are simplified representations of reality and allow for the estimation of responses of the system (e.g., production) as the process is altered or for the description and understanding of processes within the system. The objectives of the present study were to (i) test the Stockpol $^{\circledR}$ model under the conditions and as a predicting tool for ruminant production systems in Brazil, (ii) validate a herbage accumulation model based on climatic variables, and (iii) evaluate models that estimate forage intake on pasture-based animal production systems. For these purposes, the available literature was surveyed in order to 
identify the datasets that would fulfill the necessary requirements in terms of amount of information needed for the validation and evaluation exercises. The information were then catalogued in three separate datasets: pasture, animal, and economic indicators. This work allowed for the identification of research areas where information is short (such as the seasonal distribution of annual forage production as well as forage intake by grazing animals), besides the need for standardization of research methods and procedures so that research data generated in different environments and by different research groups in Brazil can be compared on the same basis. Despite the many limitations, if the existing parameters are reviewed or adjusted and/or new input variables are incorporated, the Stockpol ${ }^{\circledR}$ model may become both a research and a decision-making tool for pasture-based animal production systems in Brazil. The Photothermal Units (PU) model proved suitable as it gave adequate predictions of forage yield of Cynodon spp. grasses considering only daylength and temperature as input variables. In this model, predictions seem to be most accurate when the basetemperature is between 13 and $15^{\circ} \mathrm{C}$. In the future, more input variables, such as the hidric balance (to fine-tune the water budget) may be incorporated into the model to enhance its prediction ability. The model evaluated to predict forage intake by grazing ruminants will likely need reparametrization and/or use green leaf allowance (green leaf dry mass divided by total liveweight at any one point in time) to be useful in predicting intake on tropical pastures. The model used to predict performance gave poor estimates of weight gain, probably due to the overestimation of the energy cost of grazing and/or the underestimation of the nutritive value of the diet selected. It is expected that, once these issues have been resolved, the performance model can operate in conjunction with 
both the PU and the intake models so that the major components of the system can be simulated under Brazilian conditions 


\section{INTRODUÇÃO}

Nos sistemas agropecuários o meio-ambiente, o solo, os animais e as plantas são componentes indissociáveis no processo de produção. Além disso, nestes sistemas o tempo de produção é relativamente longo e dificilmente pode ser alterado ou interrompido sem perda de produtividade do mesmo. Um exemplo dessas características dos sistemas agropecuários pode ser apreciado ao se considerar a produção de leite de um bovino. Após o início da lactação da vaca, o processo (lactação) não pode ser interrompido (exceto pelo término dessa, pela morte ou abate do animal) e retomado em função, por exemplo, dos preços de mercado ou da falta de insumos (alimentos) a produção. Essas características especiais tornam o processo de tomada de decisão nos sistemas de produção agropecuários permeado de risco e incerteza.

A falta da informação perfeita (sem risco e/ou incerteza) resulta num problema, a inexistência de certeza sobre os resultados da implementação de qualquer uma das diversas alternativas de curso de ação sobre o sistema. Esse problema embute no cerne de qualquer decisão um certo grau de risco (probabilidade da ocorrência de um evento) e/ou incerteza (impossibilidade de estimar a probabilidade de ocorrência de um evento) da ocorrência dos resultados esperados face a um determinado curso de ação ou alternativa. Por esse motivo, sempre que possível deve-se realizar um estudo detalhado 
sobre o problema e destacar as alternativas (de solução) disponíveis para resolvê-lo com maior probabilidade de sucesso, processo denominado análise de decisão (DIAS, 1996).

O processo de análise de decisão segue o fluxo proposto por DIAS (1996):

1) Formulação do problema

2) Elaboração e resolução do modelo ou sistema de apoio à decisão

3) Interpretação dos resultados e conclusões

4) Realização dos testes de análise de sensibilidade

5) Escolha e implementação da melhor solução

Nesse contexto, pode-se inferir que uma boa metodologia de análise de decisão requer avaliação da exatidão dos dados (informações) sobre o problema e eficiência de manipulação do sistema a fim de que se possa atingir as metas planejadas (DIAS, 1996; BARIONI, 2002). Assim, a modelagem é uma técnica (ou ferramenta) que pode auxiliar o processo de tomada de decisão, uma vez que permite a simulação de vários cenários e estimar a repercussão dos diferentes cursos de ação sobre os sistemas de produção.

Além de auxiliar o processo tomada de decisão, a utilização de modelos permite descrever e compreender alguns dos processos que ocorrem dentro do sistema e as interações entre seus componentes (BELLOTI, 2000; BARRET e NEARING, 1998). Vista sob esta ótica, a utilização dos modelos pode ajudar a identificar propriedades emergentes, a quantificar os processos que ocorrem no interior dos sistemas e identificar áreas carentes de informação e/ou pesquisa.

O desenvolvimento e a utilização de modelos matemáticos pode disponibilizar aos tomadores de decisão, uma ferramenta para estimar o comportamento do sistema 
face a determinadas situações criadas pelo usuário do modelo. Deste modo pode-se realizar várias simulações e escolher, por exemplo, a alternativa que minimiza o risco ou a variância da resposta do sistema a decisão tomada (DOURADO NETO et al., 1998a; FIALHO, 1999). Este tipo de aplicação pode ser utilizado tanto num exemplo didático, numa pesquisa científica como em decisões empresariais.

Assim, devido as várias aplicações da utilização de modelos matemáticos nos sistemas de produção esse trabalho teve por objetivos avaliar:

A) O modelo Stockpo ${ }^{\circledR}$ quando rodado com dados obtidos de sistemas de produção de bovinos de corte brasileiros

B) O modelo de acúmulo de forragem em função de variáveis climáticas proposto por VILA NOVA et al. (1983) para estimar produção de forragem em função do acúmulo de unidades fototérmicas.

C) O modelo para estimar consumo de forragem em sistemas de produção de ruminantes em pastagens proposto por McCALL (1984) e desempenho animal proposto pelo STANDING COMMITTEE ON AGRICULTURE RUMINANTS SCA (1990). 


\section{REVISÃO DE LITERATURA}

\subsection{Conceitos de Sistemas e modelos matemáticos}

Os sistemas são estruturas autônomas e complexas, que apresentam limites (determinados pelas interações entre os seus componentes) e processos que ocorrem no seu interior (BARIONI et al., 2002). Os limites definem as variáveis de entrada, de saída e/ou os parâmetros dos componentes do modelo. A complexidade do sistema é determinada pela quantidade de níveis de organização do mesmo, que são identificados pela emergência de propriedades que não existiam no nível de organização imediatamente inferior ou contíguo ao estudado (LOVATTO, 2002).

As propriedades emergentes são resultantes da interação entre pelo menos dois componentes do sistema, e não existem se pelo menos um deles está sozinho. São essas propriedades que explicam por que a resposta de um componente isolado face a uma determinada ação, nem sempre é igual à observada e/ou medida quando esse se encontra no interior do sistema (BARIONI et al., 2002b). A quantidade e organização (hierarquia) dos componentes e os processos que ocorrem no interior do sistema e suas propriedades emergentes vão modular as respostas (mudanças no comportamento) desse, em função de alterações nos seus limites (BARIONI et al., 2002; LOVATTO, 2002). 
Um exemplo desses conceitos é dado na versão simplificada do modelo SEPATOU (DURU, 2002). Nesse modelo (Figura 1), os componentes são o solo, a pastagem e os animais. Os limites desse sistema definem as variáveis de entrada (ex.: quantidade de fertilizante nitrogenado, temperatura média e utilização de alimentos suplementares), a variável de saída (produção de leite dos animais). Nesse modelo, a produção de leite é o resultado da interação entre as variáveis de entrada e as propriedades emergentes do sistema ( e.g., o consumo de forragem e a capacidade de suporte do solo). O modelo pode tornar-se mais complexo inserindo-se nele níveis superiores e inferiores de organização. A inserção desse sistema de produção no âmbito da região ou país onde o mesmo se encontra caracteriza níveis superiores de organização. Assim como, os níveis inferiores de organização podem ser observados a medida que a analisa o sistema é estendida até o interior da célula ou colóide de solo. 


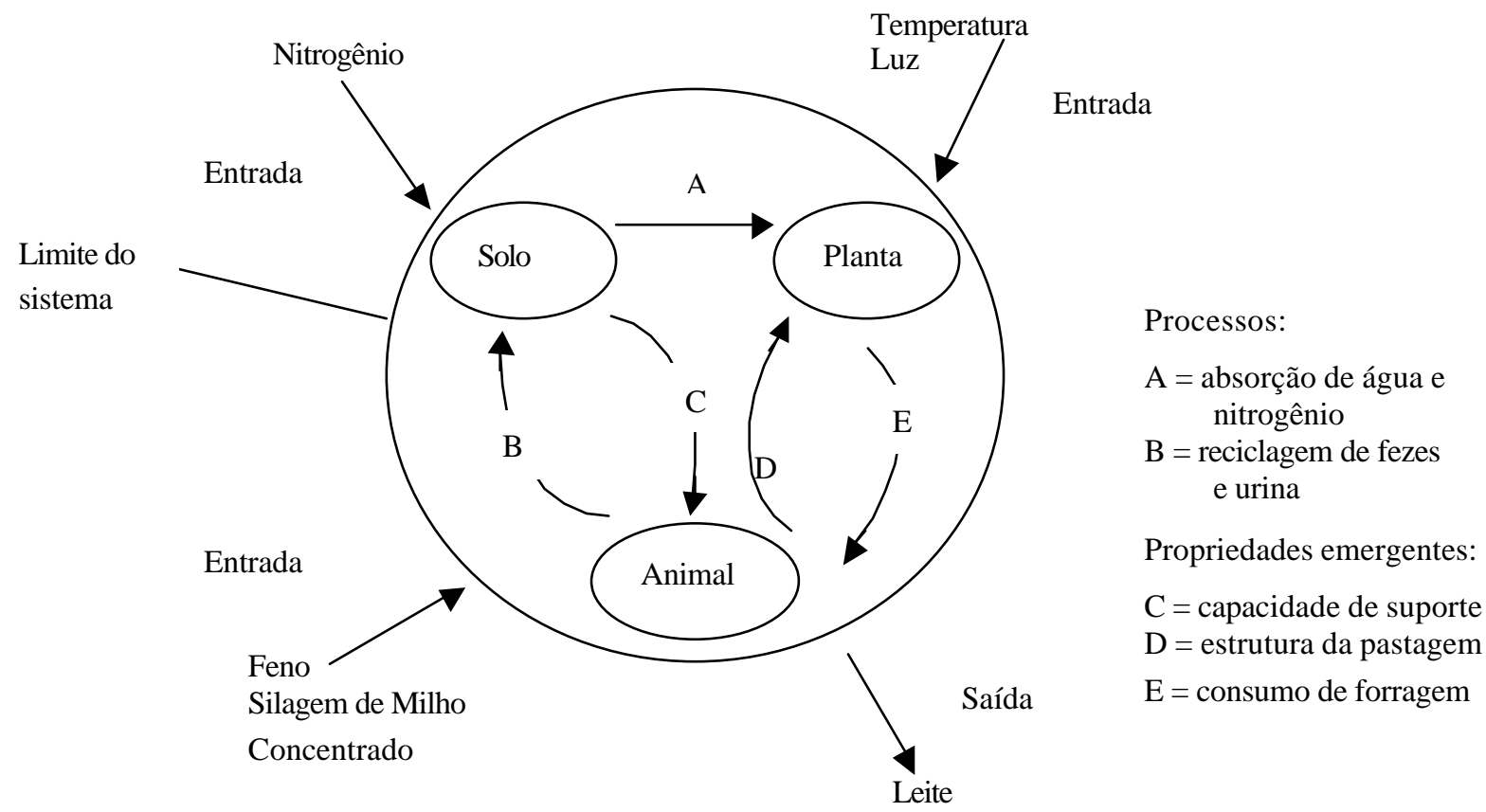

Figura 1- Representação simplificada do modelo SEPATOU. Adaptado de DÙRU (2002)

Como exemplo de interação entre os componentes do sistema (solo, planta e animal) pode-se citar a eficiência de colheita de forragem pelos animais. Essa, por sua vez, é modulada pelo consumo de forragem (propriedade emergente do sistema), visto que o consumo não existe sem que ao mesmo tempo estejam presentes o animal e a planta.

Além de descrever e/ou estimar a reação do sistema face à ação, a técnica de modelagem pode ser utilizada para orientar a execução de pesquisas e identificar áreas onde existe carência de informação (Figura 2). Assim, após a identificação do problema 
e do conhecimento prévio a construção do modelo do pode fornecer subsídios (informações) para quantificar os processos que ocorrem no interior do sistema (LOVATTO, 2002). Além disso, o processo de parametrização, avaliação e validação do modelo pode ser realizado com equipes multidisciplinares, e levar a nova experimentação e/ou utilização de resultados de outras pesquisas a fim de melhorar a eficiência analítica dos modelos. Assim, além de integrar conhecimento multidisciplinar, a modelagem de sistemas auxilia a identificação de áreas carentes de informação. Essa necessidade de informação motiva o recomeço de um ciclo virtuoso, que é a busca do conhecimento.

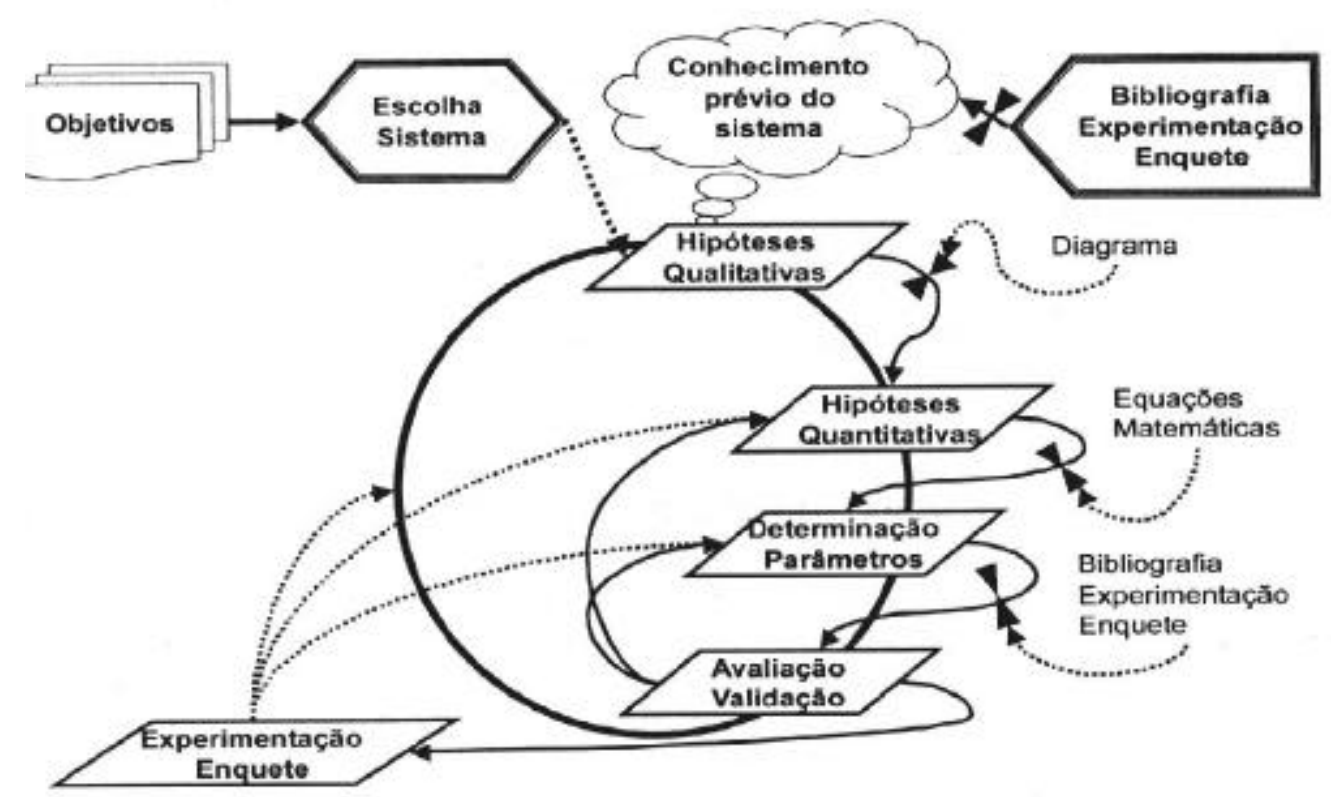

Figura 2 - Integração dos conceitos de modelagem de sistemas numa abordagem de pesquisa reducionista. Adaptado de LOVAT0 (2002). 
Por representarem uma visão simplificada da realidade os modelos carregam no seu interior duas fontes de erro relacionados a: (A) estrutura e processos considerados relevantes que se deseja modelar e (B) parametrização do modelo (DIAS, 1996). O grau e/ou a quantidade dessa simplificação depende do comportamento e conhecimento existente sobre o sistema, das informações disponíveis para a sua parametrização e da necessidade que o usuário tem da informação gerada (BARIONI, 2002; ASSIS et al., 1999; FIALHO, 1999; DIAS, 1996). Por esse motivo, os modelos devem ser tão simples quando possível e tão complexos quanto necessário para que ocorra um balanço ótimo entre os erros das estimativas e dos parâmetros modelados (BARIONI, 2002). Tendo em vista o objetivo de minimizar os erros inerentes ao modelo, deve-se identificar os objetivos da pesquisa, os usuários e beneficiários da informação gerada, a disponibilidade de informações para construção e a resolução do mesmo.

RAGSDALE (1996) propôs que a construção de um modelo deve contemplar, no mínimo, quatro etapas: (1) identificação do problema; (2) construção do modelo propriamente dito; (3) validação do modelo e (4) apresentação do resultado. Essas fases, principalmente a segunda e terceira, deverão ser repetidas quantas vezes forem necessárias para que o usuário possa ter informações confiáveis, geradas pelo modelo. Segundo STARFIELD et al. (1990) no tempo total gasto na construção do modelo devese obedecer a regra do 80/20, ou seja, $80 \%$ do tempo deverá ser gasto nos exercícios de validação e $20 \%$ na construção do modelo. A validação inclui a análise estatística do modelo para verificar se os resultados estimados são possíveis de serem alcançados em situações reais (NELSON, 1995). 
Além disso, não se deve esquecer que os modelos são uma representação simplificada da realidade e procuram estimar o funcionamento do sistema. Por esse motivo, modelo algum é capaz de decidir, isoladamente, qual a melhor alternativa. Deve-se sempre respeitar a regra do GINGO (Garbage in, Garbage out), isto é, a interpretação das saídas (resultados) do modelo devem ser realizadas levando-se em consideração a Exatidão e a representatividade dos dados de entrada e dos parâmetros utilizados, do conhecimento e experiência existentes sobre o sistema modelado pois nem sempre os resultados do modelo são factíveis com a realidade (CAIXETA FILHO, 2000; BARRET e NEARING, 1998).

Os modelos podem ser classificados em três categorias (FIALHO, 1999):

A) Físicos - representam uma visão, normalmente em menor escala que o original, de um objeto ou sistema. Ex. miniaturas de automóveis e maquetes de edifícios.

B) Conceituais ou teóricos - descrevem o sistema e/ou o seu comportamento através de teorias e ou representações gráficas, como por exemplo as interrelações existentes em um ambiente de pastagens.

C) Matemáticos - utilizam equações e inequações para representar e/ou descrever o sistema, estimando o seu comportamento face aos dados de entrada.

Os modelos matemáticos podem também ser classificados quanto ao tipo de equações que os constituem (lineares e não lineares), ao grau de explicação dos fenômenos que estimam ou descrevem (empíricos ou mecanistas), à forma com que tratam as mudanças ocorridas em relação ao tempo físico (dinâmicos ou estáticos), e ao 
tratamento estatístico de suas variáveis e dos seus parâmetros (estocásticos ou deterministas) (THORLEY, 2001; CAIXETA FILHO, 2000; FIALHO, 1999).

Os modelos lineares têm natureza normativa e são utilizados em situações que permitem a linearização do problema (CAIXETA FILHO, 2000; SOWELL e WARD, 1998; DIAS, 1996). Para que um sistema possa ser considerado linear o mesmo deve respeitar algumas condições (CAIXETA FILHO, 2000; RAGSDALE, 1997; DIAS, 1996):

A) O objetivo do problema deve ser único e visa otimizar (maximizar ou minimizar) a solução deste.

B) A função objetivo deve ser especificada e conter todas as alternativas disponíveis, chamadas de variáveis de decisão.

C) Todas as variáveis devem estar sujeitas a restrições e limites, devem possuir expoente 1 e contribuição proporcional e aditiva na função objetivo.

Os sistemas lineares permitem a simplificação da estrutura matemática reduzindo a necessidade de recursos computacionais (software e hardware) para a resolução dos mesmos. Esses modelos tem sido aplicados em diversas áreas dos sistemas de produção animal como, por exemplo, no cálculo de rações e no planejamento de fazendas (BARIONI, 2002; DIAS, 1996).

Vários componentes e fenômenos que ocorrem no interior dos sistemas agropecuários, todavia, não tem comportamento linear. Nas funções ou sistemas não lineares pelo menos uma das variáveis apresenta expoente diferente de 1, e que não permitem a linearidade e/ou aditividade das contribuições na função objetivo (CAIXETA FILHO, 2000; RAGSDALE, 1997). Dentre os exemplos de fenômenos não- 
lineares que ocorrem em sistemas de produção animal estão o acúmulo de forragem e o consumo desta pelos animais (VILLA NOVA et al., 1999; DEMMENT et al., 1995).

O acúmulo de forragem, apresenta um comportamento logístico (THORNLEY e JOHNSON 1990; TORNLEY, 2001). Este pode ser dividido em três fases: uma primeira não linear, uma linear e em seguida novamente não linear como foi demonstrado por VILLA NOVA et al. (1999). Nesses casos, os sistemas lineares descrevem adequadamente somente a fase intermediária do acúmulo.

Os modelos empíricos, também chamados "caixa preta", procuram estimar a resposta (saída) em função dos dados de entrada, sem explicar como se dá o funcionamento do mesmo (FIALHO, 1999). Nesses modelos, os parâmetros das equações são determinados através de análise de regressão. Um exemplo da aplicação de modelo tipo caixa preta foi desenvolvido por FIALHO e LEDUR (1997), e expressa a curva de produção de ovos de galinha em função do tempo. O modelo é concebido em função de quatro parâmetros: o momento do pico de postura (dias) contado a partir do início da produção da ave, a taxa de postura no pico de produção (ovos por ave por dia), o período em semanas entre o início e o pico de postura, e o decréscimo da na taxa de postura. De acordo com os resultados expressos pelo modelo é possível estimar a produção total do lote e a comparação da taxa de postura entre lotes antes do término de postura. Estes parâmetros podem ser utilizados em programas de melhoramento genético que visam a seleção de aves em função de produção e com isso diminuir-se o intervalo entre gerações, uma vez que não seria necessário esperar-se o término da postura para se comparar a produção total e a taxa de postura entre os diversos lotes de uma granja (FIALHO, 1999). 
Os modelos são definidos como mecanistas quando integram relações de causa e efeito e mais de um nível de organização. Desse modo, permitem estimar e explicar as mudanças ocorridas no sistema em resposta a alterações nas variáveis, das equações e as relações de troca entre os componentes do modelo. Dentre os vários exemplos de modelos mecanistas desenvolvidos está o proposto por WOODWARD (1997) que estima o consumo forragem por bovinos em função da massa de forragem apreendida por bocado. Esse modelo demonstra como os efeitos da estrutura e composição morfológica da forragem influenciam a massa do bocado. Além disso, o modelo é capaz de integrar e explicar parte da relação entre a massa de bocado ingerida, com as características estruturais da pastagem, a composição morfológica e o valor nutritivo da forragem, bem como estimar os efeitos da massa de bocado sobre a taxa de bocado, o tempo de pastejo, o tempo de ruminação e ócio do animal na pastagem.

Os modelos dinâmicos incluem o tempo físico entre suas variáveis e estimam ou descrevem as mudanças ocorridas e as respostas ou alterações no sistema em função desta variável, o período de tempo simulado. Em produção animal esses modelos têm várias aplicações, uma vez que os sistemas biológicos apresentam uma seqüência de mudanças relacionadas ao tempo. Por esse motivo, os modelos dinâmicos são capazes de prever os efeitos de uma decisão de manejo sobre as variáveis-respostas biológicas e sua repercussão na produção final do sistema (ASSIS et al., 1999). Vários modelos dinâmicos foram e estão sendo desenvolvidos para serem utilizados em produção animal, como, por exemplo os descritos por TATIZANA (1995), CEZAR (1982a), ORSKOV e McDONALD (1979) e BELLOTI (2001). 
BELLOTI (2001) descreveu um modelo dinâmico, o Agricultural Production Systems Simulator (APSIM), que foi desenvolvido com o objetivo de estimar a produção de grãos em função de fatores climáticos e de variação na fertilidade do solo. A utilização do APSIM permitiu a quantificação da influência dos fatores climáticos na produção vegetal e a sustentabilidade de sistemas de produção. Além disso a utilização deste modelo pode facilitar a comunicação entre pesquisadores e fazendeiros, uma vez que possibilita estimar os resultados de alterações realizadas no sistema de produção (MCCOWN et al. 1998) .

Um modelo é definido como estático quando o tempo não é uma das variáveis que o compõem. Dentre as várias aplicações de modelos estáticos estão o cálculo de ração com mínimo custo. Um exemplo da utilização deste tipo de modelo foi sugerido por ASSIS et al. (1999), para a seleção de dietas de vacas em lactação. Esse modelo utilizando o custo de produção, de colheita, de distribuição dos alimentos e a sua capacidade de resposta (expressa em produção de leite) classifica em ordem decrescente as dietas formuladas em função da relação relação benefício/custo. Segundo ASSIS et al. (1999) esse modelo poderá se tornar uma ferramenta a ser utilizada nos processos de tomada de decisão especialmente na formulação, balanceamento e seleção de dietas.

Os modelos são do tipo determinista quando não incluem em seu interior a geração de pelo menos uma variável aleatória ou incorporam o risco em suas variáveis de decisão. Assim toda vez que modelo é rodado sem alterar os dados de entrada, serão obtidos os mesmos dados de saída. CEZAR (1982a; 1982b) desenvolveu um modelo determinista para a tomada de decisão em pecuária de corte, mas citou que o uso de modelos estocásticos talvez fosse mais indicado pois contemplaria as variáveis de 
mercado e a ocorrência de eventos climáticos que efetivamente ocorrem nos sistemas agropecuários. Todavia, a carência de informação sobre os sistemas de produção brasileiros, especialmente com relação ao componente pastagem, tornaram impossível o estabelecimento desses modelos. BARRET e NEARING (1998) e NELSON (1995) relataram que mesmo nos sistemas deterministas pode-se compor um pouco de variabilidade uma vez que se trabalham com médias e nestas já estaria embutida alguma forma de variabilidade.

Os modelos estocásticos incorporam o risco e/ou a probabilidade associadas à decisão (NELSON, 1995). Isto pode ser realizado com a geração de uma variável aleatória (número entre 0 e 1 , com distribuição de probabilidade conhecida) que multiplica um ou mais parâmetros do modelo ou de técnicas que visam, por exemplo minimizar a variância e os desvios associados aos resultados estimados pelo modelo nas simulações realizadas em relação a média das observações. Nesse tipo de modelo, o processo de análise de decisão deve levar em conta a média das estimativas ou dos relatórios de saída elaborados pelo modelo. Estes modelos são úteis nas situações onde a variação é importante como por exemplo nos estudos de melhoramento genético ou produção de forragem.

TATIZANA (1995) desenvolveu um modelo estocástico de simulação de sistemas de produção de bovinos de corte. Esse autor citou que embora a modelagem tenha sido representativa do sistema, a falta de dados relacionados à produção e ao valor nutritivo da forragem e do crescimento dos animais impediu a geração de algumas variáveis estocásticas, indicando assim áreas onde há necessidade de geração de informações pela pesquisa. 
Os modelos matemáticos podem também ser classificados quanto à sua utilidade em: preditivo, descritivo ou de decisão (RAGSDALE, 1996). Segundo essa classificação, os modelos de predição seriam utilizados para prever o comportamento de um sistema face a determinados dados de entrada, independente de ser estocástico ou não. Os modelos descritivos seriam aqueles capazes de descrever o comportamento do sistema face a uma série de dados de entrada. E os modelos de decisão s̃o utilizados para auxiliar a tomada de decisão, permitindo a análise de várias alternativas e a comparação entre cenários.

Essas classificações têm a finalidade de sistematizar os objetivos e a utilidade dos modelos matemáticos. Assim, de acordo com as necessidades dos usuários e dos beneficiários (esses podem não ser a mesma pessoa) da informação, pode-se identificar a necessidade de inclusão ou não da adição de novos componentes e processos modelados, a fim de otimizar a capacidade preditiva do modelo (THORNLEY E JOHNSON, 1990; PASSIOURA, 1996).

\subsection{Modelagem matemática da dinâmica da pastagem}

Os sistemas de produção de ruminantes em pastagens (SPRP) apresentam uma organização complexa e três compartimentos característicos: o solo, a planta e o animal. Cada um desses componentes possui níveis de agregação inferiores (e.g. as células e moléculas) e superiores (e.g. a fazenda, região e/ou país). Assim, a produtividade do sistema é o resultado da interação dos seus diversos componentes (solo - planta - animal) face a alterações nos dados de entrada sejam eles naturais (e. g., alterações no 
fotoperíodo e temperatura) ou resultantes da ação gerencial, como por exemplo aumento na taxa de lotação da pastagem ou aplicação de adubação nas pastagens.

Além disso, a resposta do sistema uma ação, leva um espaço de tempo (lagtime) relativamente longo para se expressar devido a capacidade tampão dos SPRP. Essa característica organizacional dos SPRP permite o aparecimento de várias propriedades emergentes como, por exemplo, o consumo de forragem (que não existe sem a presença da planta e do animal, ao mesmo tempo no sistema), e processos como a absorção de água e a reciclagem de nutrientes. Essas propriedades emergentes modulam a resposta (produção e produtividade) do sistema (fazenda) em função de alterações no fotoperíodo, na temperatura, o aporte externo de nutrientes para os animais e as correções de solo, entre outras.

Além disso, nos SPRP a otimização da produção é resultado do somatório de eficiências parciais dos processos que ocorrem nos seus componentes (o solo, a planta e o animal). Assim, para atingir o nível ótimo de produção preservando o sistema, o tomador de decisão deverá, necessariamente, procurar atingir o equilíbrio entre as eficiências de crescimento da forragem, utilização da forragem produzida e conversão desta em produto animal (DA SILVA e SBRISSIA, 2000). Essas peculiaridades permitem que exista na mesma região, e talvez na mesma fazenda, diferentes sistemas de produção convivendo com níveis satisfatórios de produção e produtividade em virtude da realidade local.

O crescimento da forragem não é uniforme durante todos os meses do ano, pois é afetado por fatores de estresse, como a desfolha imposta pelos animais durante o pastejo e/ou disponibilidade de luz, nutrientes, água e $\mathrm{CO}_{2}$ (ALCÂNTARA et al. 1989; 
RODRIGUES et al. 1989). Esses fatores de estresse limitam o crescimento e provocam a estacionalidade na produção e no valor nutritivo desta (ROLIM, 1980).

A utilização de técnicas como irrigação, adubação e correção de solo pode amenizar a ação desses fatores de estresse e a estacionalidade da produção da pastagem. Entretanto, os efeitos do clima (fotoperíodo e a temperatura do ar) dificilmente podem ser manipulados. Isto só é possível em condições de casa de vegetação e nas simulações. Além disso, as características climáticas de cada região variam de acordo com a latitude e longitude do local e ano, incrementando o risco de se estimar a produção e o acúmulo de forragem. Assim, estimar a produção e o valor nutritivo da forragem, bem como a dinâmica da pastagem para traçar estratégias de uso desta tem sido um desafio enfrentado na hora da tomada de decisão nos sistemas de produção de bovinos em pastagens.

Dentre as ferramentas que podem ser utilizadas para estimar a produção e o acúmulo de forragem podem ser citados os modelos matemáticos que utilizam variáveis climáticas, e.g. graus-dia (GD) e unidades fototérmicas (UF). Esses modelos permitem compreender, quantificar e prever as interações entre o ambiente e a planta (NABINGER, 1997). Assim, podem ser utilizados para estimar a produção de forragem em regiões diferentes daquelas onde é medida, para elaborar o zoneamento climático e determinar temperatura base de gramíneas das forrageiras (MEDEIROS et al., 2002).

Os modelos baseados em graus-dia (GD) estimam o efeito da temperatura sobre a produção da forragem. Estes modelos podem ser lineares ou não-lineares. YIN (1995) citou que os modelos não-lineares são os mais indicados, especialmente se estimarem efeitos independentes da temperatura diurna e noturna no acúmulo de GD, para estimar a 
produção de uma cultura. Entretanto, esses por não integrarem o efeito de outros fatores ambientais que provocam variação na produção como o fotoperíodo tem recebido crítica de vários autores (BONHOMME, 2000).

A produção das plantas é resultado do efeito do clima, que condiciona a adaptação, a persistência e a produção da pastagem (RODRIGUES et al., 1989). Dentre os fatores climáticos, HODGES (1991) explicou que a produção da planta é função ação da temperatura ambiente, podendo este efeito ser modificado por outros fatores especialmente o fotoperíodo. Por esse motivo, VILLA NOVA et al. (1983) propuseram a utilização da unidade fototérmica (UF) como variável climática para estimar as respostas produtivas das culturas. A UF é uma grandeza que integra os efeitos da temperatura do ar e do fotoperíodo sobre o acúmulo de biomassa vegetal. De acordo com esses autores, a produtividade de uma cultura pode ser determinada, para as condições de ausência de déficit hídrico por uma função do tipo:

$$
\mathrm{P}=\frac{\mathrm{k}}{\mathrm{a}+\mathrm{e}^{-\mathrm{b}(\mathrm{UF})}}
$$

sendo P a produção (kg MS ha-1) "a" , "b" e "k" constantes de acordo com a espécie da forrageira, "e" é a exponencial $(2,8182)$ e UF é a quantidade de "unidades fototérmicas" acumuladas no período. Essa grandeza , a UF, ao integrar o efeito do fotoperíodo e dos graus-dia possibilita uma melhor explicação do crescimento das plantas, especialmente na primavera (LEMOS FILHO et al., 1997). Nesse período a temperatura média do ar e o fotoperíodo são crescentes, o que permite a planta otimizar a fotosíntese e suprir energia para o seu crescimento. Além disso, a função logística possibilita uma melhor 
interpretação biológica e matemática do acúmulo de forragem (THORNLEYe JOHNSON, 1990).

O acúmulo de forragem é um processo dinâmico composto por síntese de tecido (haste e folha) e desaparecimento de material morto, que não foi reabsorvido pelo sistema. Essa proporção entre a quantidade de hastes, folhas e material morto na pastagem se reflete no valor nutritivo da forragem. Assim, tão importante quanto a estimativa adequada do acúmulo é a composição morfológica da forragem acumulada. Um exemplo de modelo para estimar o acúmulo e composição morfológica da forragem na pastagem foi proposto por McCALL e BISHOP-HURLEY (2003), que desenvolveram um modelo para estimar a produção de Azevém perene(Lolium perenne L.)quando esta está em pastagem. O modelo estima a produção e a composição morfológica da forragem em função da variação no clima (fotoperíodo e temperatura), umidade e fertilidade do solo e dos efeitos do animal (remoção de tecidos) quando em pastejo. Os resultados de produção de forragem estimados pelo modelo foram semelhantes aos reportados em experimentos reais, embora aperfeiçoamentos sejam necessários para estimar a composição morfológica da pastagem, o que permitirá estimar e explicar com mais exatidão o desempenho dos animais e consequentemente a produtividade do sistema.

A produtividade de um sistema de produção de ruminantes em pastagem pode ser definida como o resultado da produção (desempenho animal médio e o número de animais presentes na pastagem) dividido pela área utilizada no processo e pelo tempo. Nesses sistemas o desempenho animal é função do consumo de forragem. Esse por sua vez é influenciado por características do próprio animal (e.g., estado fisiológico e mérito 
genético), da pastagem (e.g., qualidade e oferta de forragem), pela utilização de alimentos suplementares (e.g., silagem, feno e sais minerais), e outros fatores como temperatura do ar, ocorrência de pragas e doenças. Assim, estimar adequadamente o consumo de forragem de animais em pastejo tem sido o objetivo de vários modelos matemáticos, uma vez que o consumo é um dos elos de ligação entre os componentes planta e animal do sistema, além de ser uma das ferramentas que possibilita explicar o desempenho destes.

Dentre as características da planta que afetam o consumo pode-se citar a oferta, densidade volumétrica, composição morfológica e valor nutritivo da forragem. Além dessas características, a estrutura da pastagem (definida como o arranjo tridimensional de folhas, hastes e material morto aderido na planta) também afeta o consumo de forragem (STOBBS, 1975). Todos esses fatores são características da pastagem determinantes da massa de bocado e da seleção de sítios e horizontes de pastejo pelos animais. A massa de cada bocado associada ao número de bocados por unidade de tempo, e o período de tempo que o animal pasteja determinam o consumo diário de forragem por animal.

A dinâmica da pastagem no sistema de produção de ruminantes pode ser modelada utilizando-se o balanço forrageiro, que pode ser calculado pela equação:

$$
\mathrm{MF}_{\mathrm{t}}=\mathrm{MF}_{\mathrm{t}-1}+\mathrm{AC}_{\mathrm{t}}-\mathrm{C}_{\mathrm{t}} .
$$

$\mathrm{Na}$ qual, $\mathrm{t}$ e $\mathrm{t}$-1correspondem respectivamente ao momento final e inicial do intervalo de tempo t. $\mathrm{MF}_{\mathrm{t}}$ e $\mathrm{MF}_{\mathrm{t}-1}$ são respectivamente a massa de forragem final e inicial do período t. $\mathrm{AC}_{\mathrm{t}}$ é o acúmulo médio diário de forragem e $\mathrm{C}_{\mathrm{t}} \mathrm{o}$ consumo médio diário pelos animais em $\mathrm{t}$. 
O acúmulo de forragem pode ser estimado a partir de bancos de dados com informações regionais de produção. Todavia, os valores de acúmulo precisam, e devem, ser estimados com exatidão uma vez que a produção não é uniforme ao longo do ano, sendo influenciado entre outros fatores, pelo clima (temperatura, fotoperíodo), solo (umidade e fertilidade), e animal (remoção de tecidos e pisoteio). Assim, deve-se propor uma equação ou conjunto de equações que seja simples o suficiente mas que integre os efeitos da ação dos animais, do clima (temperatura e fotoperíodo), do solo (umidade e fertilidade) e da própria massa de forragem sobre o crescimento e valor nutritivo.

A adoção do balanço forrageiro, embora correta, assume algumas simplificações que podem comprometer a sua utilização no planejamento de sistemas de produção de ruminantes (BARIONI et al., 2002). São elas:

a) Não segregação dos componentes morfológicos (folha, colmo e material morto) e botânicos (consorcio de espécies) na massa de forragem.

b) Ausência de caracterização do estado anterior da pastagem sobre a taxa média de acúmulo de forragem.

c) Ausência do efeito de seleção da dieta pelos animais e seus efeitos na composição morfológica e botânica da pastagem.

d) Não caracterização e quantificação das perdas que ocorrem durante o pastejo.

Esses problemas levaram à necessidade de desenvolvimento de modelos matemáticos que procurem simular o pastejo. O pastejo é definido como o conjunto de ações que inclui escolher, apreender, colher, manipular e deglutir a forragem pelos animais. Essa é a propriedade emergente mais evidente dos SPRP, uma vez que é o elo entre os componentes planta e animal do sistema (WOODWARD, 1997). Assim, os 
modelos que estimam crescimento de plantas em pastagem devem estimar os efeitos dos animais (remoção de tecido, especialmente folhas), uma vez que esse processo altera as taxas de retorno de carbono e outros nutrientes para o solo (PARSONS et al., 1983). Além disso, provoca a eliminação de pontos de crescimento da planta e da área foliar fotosintetizante (CACHO, 1993). Portanto, dependendo da intensidade da desfolha, pode-se comprometer a rebrota das plantas e/ou a sustentabilidade do sistema como um todo.

No passado, os modelos matemáticos que procuravam descrever e/ou estimar o pastejo utilizavam equações empíricas de consumo em função da oferta (massa) de forragem e da produção das plantas em função dessa massa. Esses modelos foram inicialmente desenvolvidos para espécies de clima temperado $\left(\mathrm{C}_{3}\right)$, que é um grupo de gramíneas que só alonga hastes durante o período reprodutivo, e por esse motivo, os modelos consideravam a pastagem como sendo homogênea, onde o acúmulo de forragem era quase totalmente resultante da produção de folhas. Essa proposta, entretanto, é inadequada para descrever e estimar o crescimento e acúmulo de forrageiras tropicais $\left(\mathrm{C}_{4}\right)$, uma vez que nestas o alongamento de hastes ocorre durante quase todo o ano e é responsável por uma parcela significativa do crescimento das plantas (SANTOS, 1997; PINTO, 2000).

Uma alternativa para esse problema é o uso de modelos que procuram descrever os processos de crescimento e acúmulo de forragem, segregando ou dividindo o crescimento das plantas de acordo com os seus componentes morfológicos (folha, colmo e material morto). Essa análise permite a elaboração de modelos mais descritivos (mecanistas) e a elaboração de modelos de consumo em função da massa de folhas /ou 
da massa seca verde. Podem ainda ser utilizados para estimar a dinâmica da pastagem e seu efeito no desempenho dos animais do sistema. Assim, tem-se uma ferramenta para comparar diferentes taxas de lotação e estratégias de manejo da pastagem. Esse tipo de modelo tem sido utilizado em vários softwares comerciais como o Stockpol ${ }^{\circledR}$, o QGRAZE $^{\circledR}$ e o Conpasto ${ }^{\circledR}$ (STOCKPOL, 1996; WOODWARD et al., 2001; CANGIANO, 2002)

Outra abordagem para se modelar o pastejo é aquela onde se procura estimar o consumo de forragem em função da digestibilidade. Nesses modelos, assume-se que existe uma relação empírica entre a massa da forragem no pasto e aquela consumida, bem como que os animais selecionam preferencialmente porções mais digestíveis da planta, preferencialmente folhas. Esse tipo de modelo, quando testado com pastagens de gramíneas tropicais pode não estimar o consumo destas adequadamente, nessas pastagens, pode haver hastes com valor nutritivo igual ou até superior ao das folhas, embora as folhas tenham preferência (MARASCHIN, 2000).

Dada a complexidade do processo, os modelos propostos para descrever o pastejo tendem a buscar uma abordagem cada vez mais mecanística (BARIONI, 2002; WOODWARD et al., 2000; WOODWARD, 1997; UNGAR e NOY-MEIER, 1988). CANGIANNO et al. (2002) propuseram um modelo para estimar o consumo de forragem em função da altura e densidade do dossel. Segundo esses autores o consumo diário de forragem é função do produto entre o peso médio de bocado (PB), a taxa de bocado (TB) e o tempo de pastejo (TP). A taxa de consumo (PB multiplicado TB) por sua vez, é influenciada pelo tempo que o animal gasta entre a escolha do sítio de pastejo e a manipulação (apreender, arrancar, manipular e deglutir) da forragem. Por esse 
motivo a altura e densidade volumétrica são os fatores, inerentes à forragem, determinantes do consumo animal, uma vez que são essas características estruturais que vão determinar o peso médio de bocado.

WOODWARD (1997) propôs outra consideração sobre a taxa de bocado. Segundo esse autor, a taxa de bocado é constante para uma dada relação entre a massa de forragem ofertada e os seus constituintes morfológicos tanto na pastagem e como no bocado. Essa relação é função da oportunidade de seleção do animal. À medida que a seletividade é exercida pelo animal e este pode aumentar o peso de bocado ocorre a redução na taxa de bocado. Isto ocorre devido a necessidade do animal aumentar o tempo de ruminação e mastigação necessários para triturar e digerir a forragem consumida.

O tempo de pastejo (TP) é outro fator que influencia o consumo de forragem por animais em pastagens. O pastejo cessa, quando o animal atinge a saciedade metabólica, ocorre enchimento físico ou o tempo de pastejo máximo. Entretanto, nos sistemas de produção de bovinos em pastagens, o consumo pode cessar antes que uma dessas condições sejam atingidas (HODGSON, 1990). Esse fato é, possivelmente, explicado por alguma sensação de desconforto (térmico, nutricional, etc.) ou benefício-custo negativo, resultante da ação de continuar pastejando. Esse problema tem levado à necessidade de se desenvolver modelos que integrem com precisão os efeitos da oferta e digestibilidade da forragem sobre o consumo total do animal (WOODWARD et al., 1997).

Vários modelos que estimam consumo de forragem integrando esses três fatores (taxa de consumo, tempo de pastejo e digestibilidade da forragem), foram desenvolvidos 
(e. g. QGRAZE, SEPATOU), e podem ser utilizados para comparar estratégias de taxa de lotação da pastagem e sua repercussão no desempenho animal (WOODWARD, 2001; DÙRU et al., 2002). Esses modelos, entretanto, agregam vários níveis (submodelos) inferiores de informação e propriedades emergentes do sistema. Além disso, se os dados de entrada são pouco precisos pode haver a multiplicação de erros no interior do sistema, o que vai comprometer a exatidão das suas estimativas (WOODWARD et al., 2000). Por esse motivo, o usuário deve ser bastante cuidadoso ao selecionar os dados de entrada do modelo e realizar análise de sensibilidade antes de definir a estratégia de manejo que será efetivamente implantada.

\subsection{Considerações finais}

A técnica da modelagem pode ser utilizada em sistemas de produção animal como ferramenta de ensino e pesquisa pois facilita a compreensão das relações entre as variáveis do sistema, permitindo algumas vezes a descrição de seu funcionamento, a estimativa da resposta deste face várias alternativas de manejo. Deste modo, pode-se escolher e testar em experimentos reais os resultados estimados que forem mais interessantes para a solução do problema ou curiosidade que motivou o estudo.

Outra aplicação do uso de modelos matemáticos é na extensão rural e no processo de tomada de decisão em empresas agropecuárias. Nesta situação, podem ser simuladas diversas alternativas de produção e escolhida aquela considerada a mais adequadas ao perfil da fazenda e do empresário. 


\section{AVALIAÇÃo do MODELO STOCKPOL NOS SISTEMAS DE PECUÁRIA DE CORTE BRASILEIROS}

\section{Resumo}

O Stockpol ${ }^{\circledR}$ é um modelo matemático que estima o resultado de diferentes estratégias (cenários) de produção de ruminantes em pastagens ao longo de um ano agrícola, estimando o efeito de decisões de manejo sobre o desempenho dos animais, da pastagem e a repercussão dessas sobre rentabilidade da fazenda. Embora, não se conheça quais são as perspectivas de viabilização do uso do modelo Stockpol ${ }^{\circledR}$ em regiões tropicais, é possível que a adaptação desse modelo para as condições brasileiras possa trazer benefícios ao setor pecuário. Os objetivos deste trabalho foram testar a representatividade do modelo Stockpol ${ }^{\circledR}$ e identificar problemas apresentados pelo programa quando executado com dados obtidos nos sistemas de produção utilizados na pecuária de corte no Brasil. O Stockpol ${ }^{\circledR}$ superestimou a proporção de folhas e subestimou a fração colmo e material morto na pastagem, a taxa média de acúmulo de forragem e a eficiência de utilização de nitrogênio das gramíneas tropicais, quando cultivadas em condições ótimas de fertilidade do solo, clima e pluviosidade. Esses problemas relacionados à estimativa da massa e valor nutritivo da forragem tornaram indequada a comparação entre os valores estimados pelo software e os medidos em experimentos. Contudo, a utilização do Stockpol $^{\circledR}$ nas simulações com dados de pecuária 
de corte no Brasil permitiu identificar áreas carentes de pesquisa (estacionalidade de produção forrageira e estimativas de consumo de forragem por animais em pastejo) e a necessidade de se padronizar os procedimentos metodológicos, para que se possam comparar e integrar os resultados obtidos nas pesquisas e construir uma ferramenta de auxílio à tomada de decisão em sistemas de pecuária de corte.

\title{
EVALUATING THE STOCKPOL MODEL FOR BRAZILIAN BEEF
}

\section{PRODUCTION SYSTEMS}

\begin{abstract}
Stockpol $^{\circledR}$ is a mathematical model that predicts the output of different production strategies (scenarios) in pasture-based ruminant production systems over the agricltural year, estimating the effect of decision-making options on animal and pasture performance and their impact on the overall profitability of the system. Although the viability of the use of Stockpol $^{\circledR}$ in tropical areas is not known, it is possible that adapting the model to brazilian conditions may result in benefit for its livestock industry. The objectives of the present study were to test the feasability of Stockpol $^{\circledR}$ as a predicting tool and to identify possible setbacks and inconsistencies when the model is fed and run using datasets from real brazilian forage-beef systems. Stockpol ${ }^{\circledR}$ overestimated the proportion of leaf in the produced forage and underestimated the proportion of both stem and dead material, as well as the mean daily herbage accumulation rate and the nitrogen use efficiency of tropical forage grasses, when grown under optimal soil fertility and climatic conditions. These problems, related to forage
\end{abstract}


mass and nutritive value made the comparisons between actual experimental data and predicted values somewhat erratic. The simulations did, however, allow for the identification of research areas where better datasets are needed (seasonal growth of economically important forage species and forage intake of animals grazing on tropical pastures) as well as the need for the standardization of research methods in terms of pasture sampling, so that results from different tropical areas can be compared on a common basis and so that a resourceful tool is developed for aiding in decision-making in forage-beef production systems in Brazil.

\subsection{Introdução}

Os sistemas agropecuários sofrem a ação de variáveis endógenas (e. g., problemas sanitários do rebanho) e exógenas ao processo de produção (e. g., aumento ou queda no preço da carne) que resultam em risco da atividade relativamente alto. Por esse motivo o produtor rural necessita de ferramentas de apoio ao processo de tomada de decisão que permitam minimizar ou trazer a patamares aceitáveis o grau de risco assumido em cada decisão tomada.

Dentre as ferramentas que podem ser utilizadas no processo de tomada de decisão estão os modelos de simulação. Os modelos são uma abstração (representação) simplificada do sistema, que procura estimar as suas respostas e/ou explicar o seu mecanismo de funcionamento, face às alternativas de curso de ação simuladas pelo usuário (FIALHO, 1999; DOURADO NETO et al., 1998c). Embora possam se constituir numa importante ferramenta para o trabalho dos pesquisadores e produtores de gado de corte no Brasil, os modelos de simulação têm sido pouco utilizados. Dentre as razões 
para isso estão a carência de informações e a organização dos dados referentes aos sistemas de produção brasileiros, que dificulta o desenvolvimento e avaliação dos modelos matemáticos (TATIZANA, 1995; CEZAR, 1982b).

Diversos modelos estão disponíveis aos produtores e consultores e dentre as alternativas disponíveis está o Stockpol ${ }^{\circledR}$. Esse software foi desenvolvido para auxiliar o processo de tomada de decisão em fazendas de ovinocultura e bovinocultura de corte (McCALL e TITHER, 1993; STOCKPOL, 1996). O Stockpol ${ }^{\circledR}$ estima o resultados de diferentes estratégias (cenários) de produção (taxa de lotação, desempenho dos animais, massa de forragem na fazenda) ao longo de um ano agrícola (MARSHALL et al., 1991; McCALL e TITHER, 1993; WEBBY et al. 1995) e possibilita ao usuário comparar, na mesma tela de computador, até cinco cenários simultâneos. Com essa ferramenta podese estimar o efeito de estratégias de produção traçadas sobre o desempenho dos animais, da pastagem e a repercussão dessas sobre rentabilidade da fazenda (MARSHALL et al., 1991; McCALL e TITHER, 1993; WEBBY et al. 1995). Por estes motivos o Stockpol ${ }^{\circledR}$ constitui-se numa ferramenta de apoio à tomada de decisão, auxiliando os manejadores a identificar oportunidades de crescimento para a empresa agrícola e a elaborar um programa ou estratégia de manejo do pasto e dos animais na fazenda (McCALL e TITHER, 1993).

Embora não se conheça até o momento quais são as perspectivas de viabilização do uso do modelo Stockpol ${ }^{\circledR}$ em condições tropicais, é possível que a adaptação desse modelo para as condições brasileiras possa trazer benefícios ao setor pecuário. Essa ferramenta computacional pode ajudar a identificar áreas onde há carência de informações e/ou auxiliar o processo de tomada de decisão nas empresas agrícolas. 
Assim os objetivos deste trabalho foram testar a representatividade do modelo Stockpo ${ }^{\circledR}$ e identificar problemas apresentados pelo programa quando executado com dados obtidos nos sistemas de produção utilizados na pecuária de corte no Brasil.

\subsection{Material e métodos}

\subsubsection{Descrição do modelo}

O Stockpol ${ }^{\circledR}$, versão para MSDOS, é um modelo que opera de duas formas: o modo de equilíbrio e o específico. O modo de equilíbrio é indicado quando se objetiva simular o efeito de uma estratégia de manejo do rebanho num período de 12 meses. O modo específico é utilizado quando a simulação é realizada para estimar o efeito de uma política de manejo da fazenda dentro do período de um ano agrícola inferior a 12 meses (STOCKPOL, 1996).

O modelo é composto de cinco módulos: a pastagem, o animal, uma planilha de fluxo de caixa, um banco de dados com valores monetários e as constantes (zootécnicas e financeiras) para a pecuária de corte na Nova Zelândia. As equações e os parâmetros dos modelos não podem ser modificados de acordo com as necessidades dos usuários do programa. O usuário pode, entretanto, modificar os dados de entrada e com isso realizar diferentes simulações. Os resultados das simulações podem ser comparados na forma de relatórios de saída tanto na tela do computador como impressos (MARSHALL et al., 1991; STOCKPOL, 1996).

No modelo da pastagem, figura 1 , os dados de entrada são a taxa média de acúmulo de forragem (kg MS ha ${ }^{-1} \mathrm{dia}^{-1}$ ) para cada mês do ano, a área da pastagem, área de pastejo diferido ou que será utilizada para produção de grãos, de feno ou silagem. Os 
dados referentes àtaxa média de acúmulo de forragem podem ser acessados no banco de dados do programa, que disponibiliza informações sobre a produtividade média e valor nutritivo de espécies forrageiras para as condições da Nova Zelândia (STOCKPOL, 1996). O Stockpol ${ }^{\circledR}$ estabelece que a forragem pode ser subdividida em três frações: folhas, colmos e material morto. A proporção entre essas frações é calculada mês a mês em função da produção total e da época do ano. Essa subdivisão permite ao software estimar o valor nutritivo da forragem e a persistência da pastagem ao longo dos anos. Com esses dados o programa calcula a oferta de forragem e a quantidade (kg) de suplementos disponíveis para os animais e a proporção de folha, colmo e material morto da forragem durante todo o ano.

No modelo animal, figura 1, o usuário informa a composição do rebanho, o peso médio inicial e o ganho de peso médio diário estimado para cada categoria (bezerros, novilhos, novilhas, vacas com bezerro ao pé, touros e bois), época e peso de compra e de venda de animais. 
Dados de Entrada Modelo Dados de saída

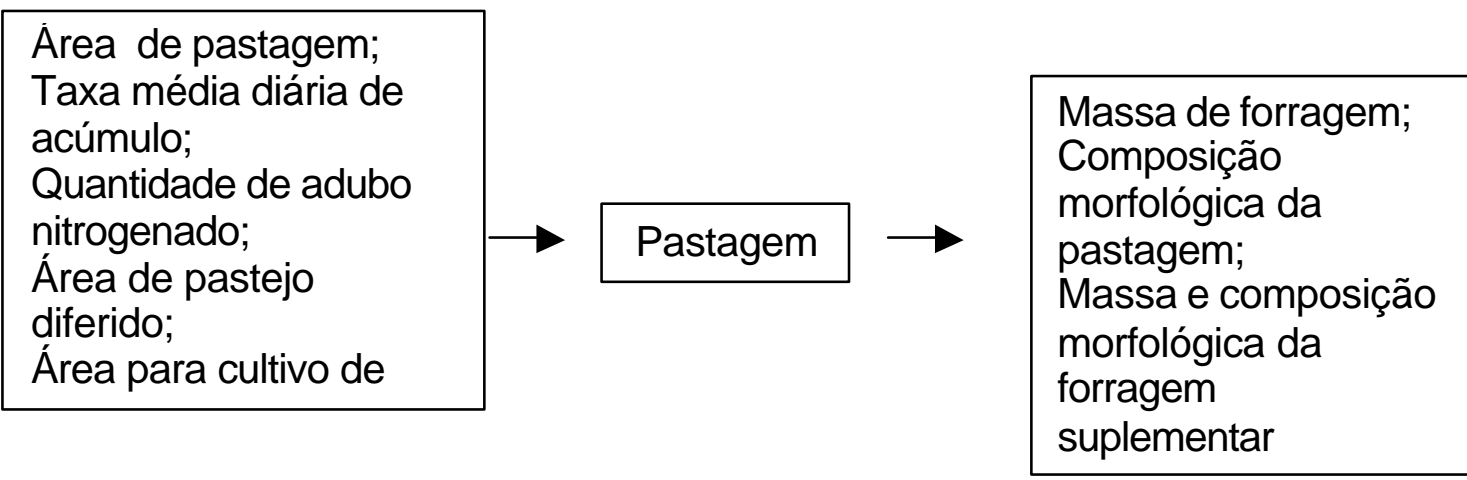

Tipo racial dos animais

Composição do

rebanho;

Peso médio de cada

animal;

Ganho de peso

estimado para cada

categoria animal;

Época e peso médio

de compra e venda de

animais

Figura 1 - Descrição esquemática do modelo do Stockpol ${ }^{\circledR}$

O Stockpo ${ }^{\circledR}$ modela o acúmulo da forragem durante período de tempo indicado pelo usuário e confronta essas informações com a necessidade de consumo do rebanho.

Desse modo o programa estima o comportamento físico da fazenda através da equação:

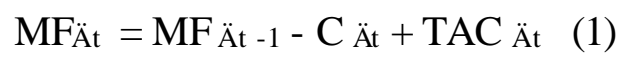


onde: $\mathrm{MF}_{\ddot{A} t}$ e $\mathrm{MF}_{\mathrm{Ät}}$-1 são respectivamente a massa de forragem presente na pastagem ao final do período de tempo $\ddot{A}_{t}$ e do período imediatamente anterior $\ddot{A} t-1$. C Ät é o consumo de forragem pelos animais e $\mathrm{TAC}_{\ddot{\mathrm{A}}}$ é a taxa de acúmulo da forragem no período $\ddot{\mathrm{A}}_{t}$ (WEBBY et al.,1995).

Assim, o Stockpol ${ }^{\circledR}$ estima se a massa, o valor nutritivo e a taxa de acúmulo de forragem são suficientes para atender as necessidades de consumo de energia metabolizável dos animais (WEBBY et al., 1995; STOCKPOL, 1996). Caso a pastagem seja insuficiente para atender as necessidades de consumo do rebanho, o usuário pode alterar os dados de entrada do modelo animal (composição, ganho de peso, época de compra e venda de animais) e/ou da pastagem (aumentar a área de pastagem e/ou utilizar suplementos - silagem, feno e concentrados). Com estes novos dados o programa estima se é possível ou não atingir os objetivos (metas) desejados pelo usuário. Além disso, esse tipo de análise permite ao usuário do modelo estimar a massa residual de folhas e com isso traçar uma estratégia de manejo que permita otimizar a utilização da forragem, a produção animal e manter o sistema em equilíbrio, evitando com isso a degradação do pasto.

Além do modelo físico, o Stockpo ${ }^{\circledR}$ elabora uma planilha de fluxo de caixa da atividade, na qual o usuário pode observar a descrição das receitas, despesas e o lucro proporcionados pelo rebanho para cada alternativa de produção simulada. A análise detalhada dessa planilha permite ao usuário estimar o desempenho econômico da atividade pecuária de corte e da fazenda e permite a comparação dos resultados econômicos de cada unidade de produção, comparando os custos, receitas e margem bruta proporcionada para cada cenário estudado (McCALL e TITHER, 1993). 
O usuário pode ainda alterar, de acordo com as suas necessidades, as constantes zootécnicas e financeiras existentes no programa. Essa alternativa ganha importância quando se analisam alternativas utilizando o modo específico do programa. Esse tipo de decisão envolve maior risco, uma vez que é tomada em função de uma condição específica e que pode mudar rapidamente no curto prazo.

\subsubsection{Organização dos bancos de dados}

Foi realizada uma pesquisa bibliográfica na Revista Brasileira de Zootecnia, Pesquisa Agropecuária Brasileira, dissertações e teses produzidas na Universidade de São Paulo (USP), Universidade Estadual Júlio de Mesquita Filho (UNESP), Universidade Federal de Viçosa (UFV) e Universidade Federal de Minas Gerais (UFMG), para identificar publicações com informações suficientes que pudessem ser utilizados nos exercícios de validação do Stockpol $^{\circledR}$. As informações disponibilizadas nos artigos selecionados foram catalogadas em três bancos de dados: (A) pastagens, (B) bovinos e (C) indicadores de preços e insumos utilizados em pecuária de corte no Brasil.

No banco de dados das plantas forrageiras foram criadas duas tabelas uma com as fontes (autores e referências bibliográficas) e outra com a espécie forrageira, a latitude e longitude do local onde foi realizado o experimento, os níveis de aplicação de fertilizantes e as taxas médias de acúmulo de forragem para cada mês do ano. Essas tabelas foram relacionadas com a referência do tipo um para um, ou seja, para cada registro de autor e trabalho só há um registro correspondente de taxa de acúmulo da espécie forrageira pesquisada. 
Nos bancos de dados de indicadores de preços de insumos e produtos da pecuária de corte foram criadas duas tabelas com as fontes (autores e referências bibliográficas) e outra com o preço e o local onde foram coletados. Esses dados foram, na medida do possível, agrupados por estado ou região. Utilizou-se tanto as médias de preços de 1990 a 2000 como os valores correntes no ano de 1999 e 2000. Essas tabelas foram relacionadas com a referência do tipo um para um, ou seja, para cada registro de autor só há um registro correspondente de local e de preço. Os relatórios de pesquisa foram compostos das informações sobre o item de preço desejado, a região, número do autor e o preço nos respectivos meses.

Dentre os trabalhos catalogados nos bancos de dados de pastagens e de desempenho animal, o trabalho de CARNEVALLI (1999) foi escolhido para se fazer a validação do programa Stockpol ${ }^{\circledR}$. Isto se deveu ao fato desse trabalho disponibilizar todas as informações necessárias (inputs) para os dados de entrada do Stockpol ${ }^{\circledR}$ e ter sido conduzido por um período superior a seis meses.

\subsubsection{Descrição do cenário simulado}

O trabalho de CARNEVELLI (1999) foi desenvolvido no Departamento de Zootecnia da USP/ESALQ. Essa autora trabalhou no período de Agosto de 1998 a Março de 1999, com pastagens de Cynodon dactylon cv. 'Florakirk', Cynodon spp. cv. 'Tifton 85' e Cynodon spp. cv. 'Coastcross'. Os pastos foram manejados sob lotação contínua com ovinos e os tratamentos foram 4 alturas constantes de 5, 10, 15 e $20 \mathrm{~cm}$.

A massa de forragem de Cynodon spp. foi estimada multiplicando-se a altura comprimida determinados por CARNEVALLI (1999) pela respectiva altura não comprimida $(5,10,15$ e $20 \mathrm{~cm})$. Os valores de massa para cada altura foram 
multiplicados pela composição de composição morfológica (porcentagem de folha, colmo e material morto) da forragem medidos por CARNEVALLI (1999). Esse procedimento tornou possível estimar, para cada mês entre setembro de 1998 a fevereiro de 1999, a massa de forragem (MF), de folhas (FO), de colmos (CO) e de material morto (MM) nas pastagens .

Foi realizada uma simulação, utilizando o $\operatorname{Stockpo}^{\circledR}$, para o mesmo período de tempo (Agosto/98 a março/99), para se avaliar os submodelos da pastagem e do animal do programa. Em ambas avaliações os dados de entrada utilizados (taxa média de acúmulo de forragem, taxa de lotação da pastagem, composição do rebanho e o peso médio dos animais por categoria) foram os mensurados e publicados por CARNEVALLI (1999).

\subsubsection{Análise estatística}

A análise estatística foi realizada utilizando-se o procedimento Proc GLM do pacote estatístico SAS ${ }^{\circledR}$, Statistical Analisys System, (SAS INSTITUTE, 1988). Os dois conjuntos de dados (o medido por CARNEVALLI (1999) e o estimado pelo Stockpol ${ }^{\circledR}$ ) foram comparados utilizando o teste " $\mathrm{t}$ ". O delineamento experimental utilizado foi inteiramente casualizado. As comparações entre o valor estimado e o observado foi realizadas sempre dentro de cada espécie utilizando-se as médias das quatro alturas para cada espécie meses do ano foram considerados as repetições. Assim, para cada forrageira estudada foi possível estimar 8 repetições. 


\subsection{Resultados e discussão}

A criação dos bancos de dados permitiu a identificação de problemas, em alguns trabalhos, como a falta de uniformidade de procedimentos metodológicos para estimar a massa e o cálculo da taxa média de acúmulo de forragem.

Vários autores, para estimar a massa de forragem (MF), realizam o corte da amostra ao nível do solo ou a uma altura pré-determinada no estudo (uniformização) e calculam a taxa de acúmulo como a diferença de massa de forragem entre o dia do corte de uniformização e o corte de coleta de amostra. Esse procedimento resulta em erro no cálculo do acúmulo e da taxa média de acúmulo de forragem, pois a forragem residual, que fica após o corte de uniformização, não é quantificada. Dessa forma, a taxa média de acúmulo é superestimada primeiros dias de crescimento, embora erro seja diluído com o aumento no período de avaliação. Isso é explicado pelo fato de que as plantas têm uma curva de crescimento do tipo sigmóide. Assim, as plantas mantidas numa altura baixa e repentinamente liberadas para crescer apresentam maior taxa de acúmulo que aquelas mantidas numa altura maior (FAGUNDES, 1999).

A determinação correta dh taxa média diária de acúmulo de forragem e a massa de forragem existente no pré-pastejo (para sistemas de lotação intermitente) ou massa média da forragem (para sistemas de lotação contínua) são os fatores que vão permitir a quantificação da MF existente na fazenda e a elaboração do orçamento forrageiro (HOLMES, 1996). Essa medida, a MF, dividida pela quantidade de unidades de peso vivo animal na área permite o calculo da oferta de forragem (OF) (THE FORAGE AND GRASSLAND TERMINOLOGY COMMITTEE - FGTC, 1992; PEDREIRA, 2002). 
A quantificação correta da OF é uma dos parâmetros que podem ser utilizados para comparar sistemas de produção animal em pastagens (HODGSON, 1990). Isto se deve ao fato de que nesses sistemas o consumo e consequentemente o desempenho de animais é o resultado da interação entre a estrutura da pastagem (oferta e arranjo espacial da forragem), o valor nutritivo da forragem, dos requerimentos nutricionais e eficiência de conversão do animal e do clima (HODGSON, 1990; STANDING COMMITTEE ON AGRICULTURE RUMINANTS - SCA, 1986; McCALL, 1990, BERCHIELLI et al., 2001, GOMIDE et al., 2001). A OF é uma medida instantânea que relaciona a massa de forragem e a massa de animais presente na pastagem num dado ponto tempo. Por esse motivo, nos sistemas de produção animal em pastagens a OF é o único fator que influencia o consumo que pode ser controlado durante a execução dos experimentos de pastejo. Isto pode ser realizado alterando-se a área e/ou a taxa de lotação da pastagem.

Outro problema relacionado aos dados disponíveis na literatura brasileira é que parte dos experimentos reportados foram com plantas em crescimento livre e realizando um corte em cada parcela sem levar e consideração o efeitos das medidas (corte) repetidas no tempo. Esse procedimento (deixar as plantas em crescimento livre) é importante para se determinar o potencial de produção das plantas e a qualidade da forragem, especialmente se o objetivo for produção de suplementos para a entressafra de forragem. Todavia, existe carência de informações sobre os efeitos da estacionalidade da produção, o valor nutritivo e a persistência da pastagem. Essas informações são necessárias para que se possa traçar estratégias de manejo que permitam otimizar a produção do sistema, mantendo a integridade do mesmo. 
Esses problemas metodológicos causaram a redução do número de referências disponíveis na literatura que puderam ser utilizados para comparar os resultados estimados pelo Stockpol ${ }^{\circledR}$ com os medidos em experimentos conduzidos no Brasil. Além disso, corroboram a afirmação de TATIZANA (1995) e CEZAR (1982a) acerca da necessidade de pesquisa (especialmente relacionados à produção e ao valor nutritivo da forragem e do crescimento dos animais) e organização das informações geradas.

O Stockpol ${ }^{\circledR}$ superestimou a proporção de folhas e subestimou a fração colmo e material morto na forragem (Tabela 1). Isso pode ser explicado pelo fato de todas as equações e parâmetros utilizados no modelo terem sido desenvolvidos para gramíneas de clima temperado $\left(\mathrm{C}_{3}\right)$. Nas espécies $\mathrm{C}_{3}$ o crescimento vegetativo de plantas depende da época do ano, e é composto somente de folhas. Por sua vez, nas gramíneas tropicais $\left(\mathrm{C}_{4}\right)$ a participação da fração colmo na forragem é significativa para o crescimento da planta (PINTO, 2000). 
Tabela 1. Massa estimada de folhas (MF), de hastes (MH) e de material morto (MM) em pastagens no período de agosto de 1998 a maio de 1999 estimada pelo modelo Stockpol e utilizando os dados medidos CARNEVALLI (1999) para Cynodon dactylon cv. 'Florakirk', Cynodon spp. cv. 'Tifton 85' e Cynodon spp. cv. 'Coastcross'

\begin{tabular}{lccc}
\hline Pastagem & MF & MH & MM \\
\hline & $-1045^{\mathrm{a}}$ & $487^{\mathrm{a}}$ & $974^{\mathrm{a}}$ \\
Stockpol & $677^{\mathrm{b}}$ & $1452^{\mathrm{b}}$ & $1373^{\mathrm{b}}$ \\
Coastcross & $775^{\mathrm{b}}$ & $2199^{\mathrm{b}}$ & $1762^{\mathrm{b}}$ \\
Tifton85 & $844^{\mathrm{b}}$ & $1812^{\mathrm{b}}$ & $1748^{\mathrm{b}}$ \\
Florakirk & &
\end{tabular}

Valores com letras diferentes na vertical são estatisticamente diferentes ( $p>0,05)$

Cada coluna é resultado da média de 8 valores estimados para o Stockpol e medidos para Coastcross, Tifton-85e Florakirk

O problema de superestimar a proporção de folhas na forragem, repercute também no valor nutritivo desta. O Stockpol ${ }^{\circledR}$ estima o valor nutritivo da forragem em função da massa e da relação entre folha, colmo e material morto. Além disso, o modelo estabelece que se não há entrada de dados de taxa de acúmulo num determinado mês ela é zero, e estima, em função dessa taxa de acúmulo nula, o valor nutritivo e a quantidade de forragem presente na pastagem. Assim o programa superestima o valor alimentar (valor nutritivo $\times$ consumo) da forragem. Isto se deve ao fato dos tecidos foliares constituírem a porção de melhor valor nutricional da planta e serem preferencialmente selecionados (em relação as frações colmo e material morto) pelos animais durante o pastejo.

Outra diferença entre gramíneas $\mathrm{C}_{3}$ e $\mathrm{C}_{4}$ está relacionada com a produção de matéria seca e a eficiência de utilização de nitrogênio. As gramíneas $\mathrm{C}_{4}$, quando 
cultivadas em condições ótimas de clima, fertilidade de solo e pluviosidade têm maior produção de MS, maior eficiência de utilização de nitrogênio e menor valor nutritivo que as $\mathrm{C}_{3}$. Por esse motivo, o algoritmo do programa subestima a taxa média de acúmulo de forragem e a eficiência de utilização de nitrogênio das gramíneas tropicais, quando cultivadas em condições ótimas de fertilidade do solo, clima e pluviosidade.

$\mathrm{Na}$ análise de sensibilidade realizada com o submodelo da pastagem do Stockpol $^{\circledR}$, testou-se os limites de taxa média de acúmulo de forragem e eficiência de utilização de nitrogênio do programa. Nesse exercício, verificou-se que a máxima taxa de acúmulo de forragem permitida é de $200 \mathrm{~kg} \mathrm{MS} \mathrm{ha}^{-1}$ dia $^{-1}$ a máxima eficiência de utilização do nitrogênio (N) é de $30 \mathrm{~kg}$ MS produzido para cada $\mathrm{kg}$ de $\mathrm{N}$ fornecido. As gramíneas tropicais, é sabido, podem atingir taxas de acúmulo maiores que esse valor, conforme reportado por BRAGA (2001). Esse autor, determinou taxas de acúmulo de forragem de até $350 \mathrm{~kg} \mathrm{MS} \mathrm{ha-1}$ dia $^{-1}$ e eficiência médias de 90,6 $\mathrm{kg}$ MS para cada $\mathrm{kg}$ de $\mathrm{N}$ fornecido, para capim Mombaça (Panicum maximum Jacq.) cortado a cada 28 dias e adubado com 0, 250 e $500 \mathrm{~kg}$ de nitrogênio por hectare/ano em Pirassununga-SP.

As inadequações do modelo para estimar a massa e o valor nutritivo da forragem tornaram inconsistente a correspondência entre os valores estimados pelo Stockpol e os observados por CARNEVALLI (1999). Além disso, modelo não permite que se componha o rebanho ovinos, somente com animais machos. Essa restrição, foi outro fator que impediu a avaliação adequada do modelo animal utilizando-se os valores medidos por CARNEVALLI (1999).

$\mathrm{Na}$ análise de sensibilidade do modelo identificourse a impossibilidade de se mudar o período do ano agrícola e composição do rebanho. Essas características do 
modelo tornaram inadequada a comparação entre os valores estimados e aqueles medidos que estavam catalogados no banco de dados de animais, uma vez que para essas situações os animais devem ficar mais de 12 meses no rebanho, o que não condiz com a realidade.

No modelo Stockpol ${ }^{\circledR}$ o ano agrícola sempre começa no dia primeiro de julho e termina dia 30 de junho. Essa rotina torna impossível a tarefa de realizar uma simulação onde se compra animais em junho para vendê-los, por exemplo, em novembro de um mesmo ano agrícola. Para esses casos, a simulação só é possível quando se permite que os animais mudem de categoria, e permaneçam na fazenda durante mais de um ano agrícola. Além disso, a estação de monta dos animais primíparos ocorre sempre quando esses estão próximos aos 14 ou 26 meses, independente do peso. Esses fatos seriam justificados na Nova Zelândia onde o manejo do rebanho procura utilizar ao máximo a estação de crescimento da pastagem e esta ocorre no mesmo período em todo o país. Entretanto, não é adequado às condições brasileiras, onde as estações de crescimento podem ocorrer - de acordo com a região - em meses diferentes daquele país (Nova Zelândia) e o manejo do rebanho frequiêntemente não é estacional.

Outra limitação é que o Stockpol $^{\circledR}$ não trabalha com animais de raças zebuínas (Bos indicus), bastante utilizadas no Brasil, e que tem comportamento ingestivo e reprodutivo diferente dos Bos taurus (FREER et al, 1995; SCA, 1990). Por esse motivo o modelo necessitará de novos parâmetros para a correta estimativa de consumo dos animais zebus ou provenientes de cruzamentos entre Bos taurus e Bos indicus. 
O programa disponibiliza custos de produção de insumos e de animais para as condições neozelandesas que podem ser substituídas por dados brasileiros, sem alterar a rotina do programa.

\subsection{Conclusões}

Apesar das limitações encontradas, o Stockpol $^{\circledR}$ necessita de poucos recursos computacionais para ser utilizado, possibilitado ao usuário operá-lo com computadores “antigos", diminuindo assim o custo de aquisição de máquinas novas e/ou caras. Uma outra virtude do modelo é que ele permite a divisão da fazenda em áreas, que podem ser destinadas, por exemplo, à produção de feno, silagem, grãos ou pastejo diferido, durante alguns meses ou o ano inteiro. Isso possibilita ao tomador de decisão realizar exercícios de simulação testando a viabilidade de produzir ou comprar forragem, e suplementos volumosos ou concentrados.

Se forem realizados ajustes nos parâmetros e/ou a inclusão de novas variáveis, o Stockpol® poderá vir a ser uma ferramenta de auxílio à pesquisa e ao processo de tomada de decisão nas fazendas de pecuária de corte do Brasil. Além disso, a utilização do Stockpol $^{\circledR}$ nas simulações com dados de pecuária de corte no Brasil permitiu identificar áreas carentes de pesquisa (estacionalidade de produção forrageira e medir o consumo de animais em pastagem) e a necessidade de se padronizar os procedimentos metodológicos. Isso é necessário para que se possa comparar e integrar os resultados obtidos nas pesquisas e construir uma ferramenta de auxílio à tomada de decisão utilizada por pesquisadores, consultores e produtores rurais. 
Além disso, vários dos conceitos e estruturas utilizados no Stockpo $^{\circledR}$ podem servir como guia para o desenvolvimento de outros modelos de simulação mais adequados para os sistemas de produção animal em pastagens no Brasil. Com isso, podese economizar recursos no desenvolvimento de modelos e ferramentas para auxílio ao processo de tomada de decisão em sistemas de produção de ruminantes no Brasil. 


\section{AVALIAÇÃO DE UM MODELO MATEMÁTICO PARA ESTIMAR O ACÚMULO DE FORRAGEM EM FUNÇÃO DE VARIÁVEIS CLIMÁTICAS}

\section{Resumo}

Estimar o acúmulo de forragem ao longo dos meses do ano, como resultado do crescimento estacional das espécies forrageiras, é um desafio enfrentado na hora do planejamento sistemas de produção de bovinos em pastagens. Este trabalho teve por objetivo avaliar o modelo parametrizado para estimar o acúmulo de forragem em função do acúmulo de unidades fototérmicas (UF) para gramíneas Cynodon spp. Os resultados estimados pelo modelo UF foram comparados aos medidos utilizando-se regressão linear. O modelo estimou adequadamente a taxa de acúmulo de forragem para as gramíneas estudadas e a temperatura base inferior das espécies estudadas foi calculada entre 13 e $15{ }^{\circ} \mathrm{C}$. À medida que se diminuiu o período de tempo simulado ocorreu o incremento no erro do modelo. Por esse motivo a modelo deve ser utilizado para realizar estimativa de produção de forragem durante períodos superiores a 28 dias, quando o erro percentual é minimizado. Além disso, o modelo demonstrou que a temperatura é o principal fator climático a determinar a estacionalidade da pastagem na região de Piracicaba, SP, efeito este, todavia, que é modificado pelo fotoperíodo. 


\title{
EVALUATING A MATHEMATICAL MODEL FOR THE PREDICTION OF HERBAGE ACCUMULATION AS A FUNCTION OF CLIMATIC VARIABLES
}

\begin{abstract}
Predicting monthly herbage accumulation throughout the year as a result of seasonal growth patterns reported for tropical grasses is a challenging task when planning pasture-based livestock production systems. The objective of the present study was to evaluate a model that predicts herbage accumulation on Cynodon spp. pastures as a function of photothermal units (PU). Predicted results from the PU model were contrasted with actual herbage accumulation values using linear regression. The model was able to predict herbage accumulation rates adequately and the base-temperature values ranged from 13 and $15{ }^{\circ} \mathrm{C}$. As the duration of the accumulation period was shortened, the error of the prediction was increased. This led to the recommendation that the model be used for grazing cycles where the regrowth interval is equal to or longer than 28 days. In addition, the model showed that temperature is the major environmental constraint to forage growth in Piracicaba, SP, although it compounds with daylength in determining the yield response
\end{abstract}

\subsection{Introdução}

Estimar a produção de forragem ao longo do ano é um desafio enfrentado na hora do planejamento sistemas de produção de bovinos em pastagens e uma das razões para isso é o crescimento estacional das plantas forrageiras (ROLIM, 1980). Dentre os fatores 
responsáveis pela estacionalidade podem ser citados o clima (temperatura e fotoperíodo), disponibilidade de nutrientes e água (ALCÂNTARA et al. 1989; RODRIGUES et al. 1989; ROLIM, 1980). A utilização de técnicas como irrigação, correção e adubação do solo pode amenizar a estacionalidade da produção da pastagem.

Os efeitos do clima dificilmente podem ser manipulados, exceto sob condições de casa de vegetação e/ou em simulações. Além disso, a temperatura e o fotoperíodo são os principais condicionantes (na ausência de outro fator limitante do crescimento) da adaptação, da persistência e da produção da pastagem (RODRIGUES et al., 1989). Assim, o entendimento e a racionalização da resposta da planta ao fotoperíodo e à temperatura possibilitaria ao manejador da pastagem estimar a produção de forragem ao longo do ano. Dentre as ferramentas que podem ser utilizadas com este propósito (estimar a produção de forragem) estão os modelos matemáticos que estimam a resposta das plantas utilizando variáveis climáticas, os quais permitem compreender, quantificar e prever as interações entre o ambiente e a planta (NABINGER, 1997).

HODGES (1990) citou que o crescimento das plantas forrageiras é afetado primeiramente pela temperatura, embora esse efeito seja modificado pelo fotoperíodo. Uma das explicações para este fenômeno é que a temperatura é um dos mecanismos reguladores do metabolismo da planta (BONHOMME, 2000). Por outro lado, o número de horas e a qualidade (tipo de radiação) da luz disponível e interceptada pela planta afetam a fotosíntese, que por sua vez vai prover energia para a manutenção e o crescimento desta (SQUIRE, 1990). Como existe um efeito integrado da ação do fotoperíodo e da temperatura sobre as plantas, VILLA NOVA et al. (1983) propuseram a utilização da unidade fototérmica (UF) como variável climática para estimar as respostas 
produtivas das culturas. De acordo com esses autores, a produtividade de uma cultura pode ser determinada, para as condições de ausência de déficit hídrico por uma função sigmóide do tipo:

$$
\mathrm{P}=\frac{\mathrm{k}}{\mathrm{a}+\mathrm{e}^{-\mathrm{b}(\mathrm{UF})}}
$$

sendo $\mathrm{P}$ a produtividade ( $\mathrm{kg} \mathrm{MS} \mathrm{ha}{ }^{-1}$ ) em um dado intervalo de tempo, "a" , "b" e "k" constantes de acordo com a espécie da forrageira, "e" é a exponencial $(2,8182)$ e UF é a quantidade de "unidades fototérmicas" acumuladas no período (VILLA NOVA et al., 1983).

Utilizando os conceitos propostos por VILLA NOVA et al. (1983; 1999), MEDEIROS et al. (2001) parametrizaram o modelo de UF para estimar o acúmulo de forragem e a produção de Cynodon spp. Entretanto MEDEIROS et al. (2001) citaram que a falta de dados disponíveis na literatura impediu a validação do modelo sob condições irrigadas, para as quais foi parametrizado. Assim, este trabalho tem por objetivo validar o modelo parametrizado por MEDEIROS et al. (2001) para Cynodon spp.

\subsection{Material e métodos}

\subsubsection{Cálculo da quantidade de Unidades Fototérmicas}

O cálculo da quantidade de Unidades Fototérmicas acumuladas no período de tempo determinado é obtido utilizando-se a equação (2) proposta por VILLA NOVA et al. (1983): 
$\mathrm{UF}=\frac{\frac{\mathrm{n}}{2} \overline{\mathrm{GD}}^{\frac{\mathrm{Nf}}{\mathrm{Ni}}+1}}{\frac{\mathrm{Nf}}{\mathrm{Ni}}+1}$

UF = Número de unidades fototérmicas correspondente ao período de $n$ dias de desenvolvimento após a desfolha,

GD = Graus-dia médio do período de $n$ dias,

$\mathrm{Nf}=$ Valor do fotoperíodo (horas e décimos) no final do período de crescimento, e

$\mathrm{Ni}=$ Valor do fotoperíodo no início do período de crescimento.

Os valores de $\mathrm{Nf}$ e Ni para diferentes latitudes e épocas do ano podem ser obtidos por tabelas elaboradas por VILA NOVA (1978).

O cálculo dos graus-dia é realizado utilizando-se a equação (3) ou (4).

$$
\begin{aligned}
& G D=\left(T_{M}-T_{B}\right)-C \\
& G D=\frac{\left(T x-T_{B}\right)^{2}}{2\left(T_{x}-T_{M}\right)}(4)
\end{aligned}
$$

Onde:

GD é a quantidade de graus-dia acumuladas no período de tempo $n\left({ }^{\circ} \mathrm{C} \times \operatorname{dia}^{-1}\right)$.

Tx é a média das temperaturas do ar máximas no período $\mathrm{n}\left({ }^{\circ} \mathrm{C}\right)$.

$\mathrm{T}_{\mathrm{M}}$ é a média das temperaturas do ar mínimas no período $\mathrm{n}\left({ }^{\circ} \mathrm{C}\right)$.

T é a média da temperatura do ar média no período $\mathrm{n}\left({ }^{\circ} \mathrm{C}\right)$.

$\mathrm{T}_{\mathrm{B}}$ é a temperatura base inferior da planta $\left({ }^{\circ} \mathrm{C}\right)$ 
A equação (3) é utilizada quando a temperatura média é maior que a $T_{B}$. Nas situações onde a $T_{M}$ é menor que $T_{B}$ utiliza-se a equação (4). A correção proposta (5), deve ser utilizada quando a média das temperaturas do ar máximas for superior a $30{ }^{\circ} \mathrm{C}$ :

$$
C=\frac{(T x-30)^{2}}{2\left(T_{x}-T_{M}\right)}
$$

A função de produção para Cynodon spp. utilizada foi proposta por MEDEIROS et al. (2001) foi:

$$
P=\frac{9.87}{1+\exp \left(1.693-1.282 \times 10^{-4} U F\right)}-1.53
$$

\subsubsection{Dados utilizados na validação do modelo}

Os resultados estimados pelo modelo foram comparados aos medidos por TONATO $^{1}$ cujos resultados foram publicados por TONATO et al. (2002). Esses autores estimaram o acúmulo de forragem, a cada 28 ou 42 dias, para cinco cultivares de Cynodon (Florico, Florona, Estrela, Coastcross e Tifton 85) em área irrigada e adubada com $400 \mathrm{~kg}$ de $\mathrm{N}$ e $\mathrm{K}_{2} \mathrm{O}$ por ha por ano, de dezembro de 2000 e janeiro de 2002. Assim, as parcelas submetidas a intervalos entre cortes de 28 e 42 dias foram cortadas, respectivamente, 13 e 9 vezes durante a realização do experimento.

O acúmulo de forragem foi calculado pela diferença entre a massa de forragem residual (quantificada no dia zero ou após a colheita) e no dia 28 ou 42 de crescimento, de acordo com a frequiência de corte. A taxa média diária de acúmulo de forragem, foi

${ }^{1}$ Comunicação pessoal 
calculada dividindo-se a massa de a forragem acumulada pelo período de crescimento para o respectivo intervalo entre cortes, 28 ou 42 dias.

\subsubsection{Análise de sensibilidade}

Foi realizada a análise de sensibilidade dos parâmetros temperatura base inferior $\left(\mathrm{T}_{\mathrm{B}}\right)$ e da capacidade de previsão do modelo para períodos de tempo (n) de 7, 1421 e 28 dias, do efeito do fotoperíodo e da temperatura média do ar sobre o acúmulo de forragem.

A análise de sensibilidade do modelo para o parâmetro $T_{B}$ foi realizada variandose as temperaturas base em um grau de 12 a 16 úC e comparando-se os valores estimados aos medidos por TONATO et al. (2002) utilizando o coeficiente de determinação do modelo $\left(\mathrm{R}^{2}\right)$.

A avaliação dos efeitos do período de tempo (n) foi feita nos meses de janeiro (verão) e julho (inverno). Esses meses foram escolhidos pois caracterizam as estações do verão e inverno, onde ocorrem respectivamente a maior e menor produção de forragem. Para essa avaliação foi simulada a produção de forragem nos meses de janeiro e julho a cada 7, 14, 21 e 28 dias, todas elas sem que as temperaturas média, máxima e mínima fossem alteradas. Os valores de acúmulo de forragem foram estimados a cada 7, 14, 21, 28 e 31 dias divididos pelo respectivo período de crescimento, para a determinação da taxa média diária de acúmulo de forragem (TAF). Assim a TAF média diária foi estimada a cada 7, 14, 21 e 28 dias foram comparados com relação à estimada para 31 dias de crescimento, considerado o valor de referência (100\%). 
A análise de sensibilidade do modelo para o fotoperíodo foi estimada fixando-se a temperatura média $\left(25^{\circ} \mathrm{C}\right)$ e $\mathrm{T}_{\mathrm{B}}$ inferior $\left(13^{\circ} \mathrm{C}\right)$ durante todos os meses do ano. Nesta avaliação, a o único fator de variação e causa de estacionalidade foi o fotoperíodo. A sensibilidade do modelo para a temperatura média do ar foi realizada fixando-se o fotoperíodo inicial $(\mathrm{Ni})$ e final $(\mathrm{Nf})$ em 13,31, bem como a relação $\mathrm{Nf} / \mathrm{Ni}$ igual a 1 durante todos os meses do ano. Nessa análise foram utilizadas as temperaturas médias, máximas e mínimas medidas pela estação meteorológica do Departamento de Ciências $\begin{array}{llllll}\text { Exatas da } & \text { ESALQ medidas durante } & \text { ano de } & \end{array}$ (http://www.ciagri.usp.br/ emdabreu/MEDIAS.TXT). Essa metodologia permitiu isolar os efeitos, respectivamente, do fotoperíodo e da temperatura média do ar no modelo.

\subsubsection{Análise estatística}

Foi realizada uma análise de regressão linear entre os resultados medidos por TONATO et al. (2002) e os estimados pelo modelo de UF utilizando o procedimento Proc REG do pacote estatístico SAS ${ }^{\circledR}$ (SAS INSTITUTE, 1988).

A hipótese de nulidade $\left(\mathrm{H}_{0}\right)$ testada foi : $\mathrm{Y}=\hat{\mathrm{a}} 0+\hat{\mathrm{a}} 1 \mathrm{X}$; onde $=\hat{\mathrm{a}} 0$ e $\mathrm{a} 1=1$. Foi realizado o teste "f" para avaliar o grau de significância dos parâmetros â0 e â1. O coeficiente de determinação $\left(\mathrm{R}^{2}\right)$ calculado pela metodologia proposta por (KVALSET, 1985) :

$$
R^{2}=1-\left[i\left(X_{i}-Y_{i}\right)^{2} /\left(X_{i}-X_{m}\right)^{2}\right]
$$

Onde, 
$\mathrm{X}_{\mathrm{i}}$ corresponde produção medida no período de tempo ị $\mathrm{Y}_{\mathrm{i}}$ a produção estimada para o período i e $X_{m}$ é a média aritmética da produção medida durante todo o período do experimento.

\subsection{Resultados e discussão}

O modelo estimou corretamente $(\hat{a} 0=0$ e $\hat{a}=1)$ a taxa de acúmulo de forragem para as gramíneas estudadas $(\mathrm{P}=0.005)$, tabelas 1 e 2 . A temperatura base inferior das espécies avaliadas está entre 13 e $14{ }^{\circ} \mathrm{C}$, concordando com MEDEIROS et al. (2001). 
Tabela 1. Taxa média diária de acúmulo de forragem $\left(\mathrm{kg} \mathrm{ha}^{-1} \mathrm{dia}^{-1}\right)$ medida por TONATO et al. (2002) (TAF) e estimada (TB = 12, 13, 14, 15 e a 16) usando o modelo da unidade fototérmica (UF) para Cynodon spp. (Florico, Florona, Estrela, Coastcross e Tifton 85) de 20 dezembro/2000 a 21 de dezembro/2001 cortado a cada 28 dias

\begin{tabular}{|c|c|c|c|c|c|c|}
\hline Parâmetros & Medido & $\mathrm{TB}=12$ & $\mathrm{~TB}=13$ & $\mathrm{~TB}=14$ & $\mathrm{~TB}=15$ & $\mathrm{~TB}=16$ \\
\hline \multicolumn{7}{|c|}{ Florico } \\
\hline TAF & 64 & 84 & 66 & 51 & 39 & 28 \\
\hline $\mathrm{R}^{2}$ & & 0,34 & 0,78 & 0,70 & 0,28 & $-0,29$ \\
\hline \multicolumn{7}{|c|}{ Florona } \\
\hline TAF & 57 & 105 & 84 & 66 & 51 & 39 \\
\hline $\mathrm{R}^{2}$ & & 0,33 & 0,80 & 0,71 & 0,24 & $-0,39$ \\
\hline \multicolumn{7}{|c|}{ Tifton 85} \\
\hline TAF & 68 & 84 & 66 & 51 & 39 & 28 \\
\hline $\mathrm{R}^{2}$ & & 0,83 & 0,95 & 0,92 & 0,80 & 0,64 \\
\hline \multicolumn{7}{|c|}{ C. Cross } \\
\hline TAF & 60 & 84 & 66 & 51 & 39 & 28 \\
\hline $\mathrm{R}^{2}$ & & 0,31 & 0,80 & 0,30 & $-0,12$ & $-0,71$ \\
\hline \multicolumn{7}{|c|}{ Estrela } \\
\hline TAF & 63 & 84 & 66 & 51 & 39 & 28 \\
\hline $\mathrm{R}^{2}$ & & 0,31 & 0,80 & 0,69 & 0,21 & $-0,44$ \\
\hline
\end{tabular}

C. cross $=$ Coast cross 
Tabela 2. Taxa média diária de acúmulo de forragem $\left(\mathrm{kg} \mathrm{ha}^{-1} \mathrm{dia}^{-1}\right)$ medida por TONATO et al. (2002) (TAF) e estimada (TB $=12,13,14,15$ e a 16) usando o UFModel para Cynodon spp. (Florico, Florona, Estrela, Coastcross e Tifton 85) de 20 dezembro/2000 a 21 de dezembro/2001 cortado a cada 42 dias

\begin{tabular}{|c|c|c|c|c|c|c|}
\hline Parâmetro & Medido & $\mathrm{TB}=12$ & $\mathrm{~TB}=13$ & $\mathrm{~TB}=14$ & $\mathrm{~TB}=15$ & $\mathrm{~TB}=16$ \\
\hline TAF & 78 & 122 & $\begin{array}{c}\text { Florico } \\
101\end{array}$ & 80 & 59 & 43 \\
\hline $\mathrm{R}^{2}$ & & $-1,06$ & 0,06 & 0,60 & 1,00 & 1,00 \\
\hline TAF & 77 & 122 & $\begin{array}{c}\text { Florona } \\
101\end{array}$ & 80 & 59 & 43 \\
\hline $\mathrm{R}^{2}$ & & $-1,52$ & $-0,10$ & 0,60 & 0,91 & 0,79 \\
\hline TAF & 80 & 122 & $\begin{array}{c}\text { Tifton } 85 \\
101\end{array}$ & 80 & 59 & 43 \\
\hline $\mathrm{R}^{2}$ & & $-0,28$ & 0,40 & 0,68 & 0,87 & 0,75 \\
\hline TAF & 72 & 122 & $\begin{array}{c}\text { Ccross } \\
101\end{array}$ & 80 & 59 & 43 \\
\hline $\mathrm{R}^{2}$ & & $-1,60$ & $-0,19$ & 0,61 & 0,93 & 0,82 \\
\hline TAF & 72 & 122 & $\begin{array}{c}\text { Estrela } \\
101\end{array}$ & 80 & 59 & 43 \\
\hline $\mathrm{R}^{2}$ & & $-2,98$ & $-0,19$ & 0,61 & 0,61 & 0,04 \\
\hline
\end{tabular}


Nas simulações realizadas com períodos de acúmulo (intervalo entre cortes) de 42 dias o coeficiente de determinação aumenta quando se utiliza a temperatura base inferior de $15^{\circ} \mathrm{C}$. Isso se deve possivelmente à incapacidade do modelo de estimar os efeitos de frentes frias, que provocam a diminuição da temperatura média do ar durante intervalos de tempo relativamente curtos (de 1 a 3 dias) quando comparados ao período de acúmulo estimado (42 dias). Esse fenômeno ocorre principalmente no outono e primavera, quando se registram as maiores variâncias na temperatura média do ar. Assim a utilização da temperatura base inferior maior $\left(14^{\circ} \mathrm{C}\right)$ corrige parte desse erro, e melhora o coeficiente de determinação do modelo.

Para os dois meses simulados, à medida que se diminui o período de tempo simulado ocorre o incremento no erro do modelo (Tabelas 3 e 4). Possivelmente, isso é devido ao efeito multiplicativo dessa variável de entrada número de dias (n) sobre o cálculo da quantidade de unidades fototérmicas acumuladas. Assim, enquanto o número de dias do mês é multiplicado por 4,5 o valor de UF é 17,7 vezes maior em julho e 21 vezes em janeiro.

Por esse motivo o modelo deve ser utilizado para realizar estimativa de produção de forragem durante períodos superiores a 28 dias, quando o erro percentual é inferior a $20 \%$. Esse erro (20\%) é inferior ao coeficiente de variação da massa de forragem medido no experimento. Além disso, o erro é considerado aceitável uma vez que a variabilidade das medidas é resultante de uma amostra e não de toda a população, além do que a estimativa da taxa de acúmulo de forragem é uma variável bastante instável. 
Estimativas de produção de forragem para períodos curtos podem ser realizadas desde que o usuário simule o acúmulo de unidades fototérmicas para um mês inteiro e divida o valor calculado pelo número de dias do período simulado. Assim, pode-se corrigir o erro da estimativa da quantidade de unidades fototérmicas disponíveis para a planta.

Tabela 3. Estimativa de taxa média diária de acúmulo de forragem (TAF) utilizando o modelo de unidades fototérmicas (UF) em para estimar produção de forragem em intervalos de 7, 14, 21, 28 e 31 dias de crescimento nos mês de janeiro simulado para Piracicaba-SP, Latitude 22.41. A média das temperatura máximas, mínimas e média utilizada foi 31,20 e $24^{\circ} \mathrm{C}$

\begin{tabular}{cccccc}
\hline Inicio & Fim & Dias & UF & TAF & VR \\
\hline $01 / 1$ & $07 / 01$ & 7 & 533 & 13 & $\%$ \\
$08 / 1$ & $14 / 01$ & 7 & 531 & 13 & 19 \\
$15 / 01$ & $21 / 01$ & 7 & 530 & 13 & 19 \\
$22 / 01$ & $28 / 01$ & 7 & 528 & 13 & 18 \\
$01 / 01$ & $14-/ 01$ & 14 & 2091 & 27 & 38 \\
$15 / 01$ & $28 / 01$ & 14 & 2053 & 27 & 37 \\
$01 / 01$ & $21 / 01$ & 21 & 4573 & 44 & 61 \\
$01 / 01$ & $28 / 01$ & 28 & 7837 & 63 & 88 \\
$01 / 01$ & $31 / 01$ & 31 & 9436 & 72 & 100 \\
\hline VR= valor relativo, estimado em função da TAC de 31 dias. & & & \\
\hline
\end{tabular}


Tabela 4. Estimativa de taxa de acúmulo médio diário (TAF) de forragem utilizando o modelo de unidades fototérmicas (UF) em para estimar produção de forragem em intervalos de 7, 14, 21, 28 e 31 dias de crescimento nos mês de janeiro simulado para Piracicaba-SP, Latitude 22.41. A média das temperatura máximas, mínimas e média utilizada foi 31,20 e $24^{\circ} \mathrm{C}$

\begin{tabular}{cccccc}
\hline Inicio & Fim & Dias & UF & TAF & VR \\
\hline $01-07$ & $07-07$ & 7 & 196 & 5 & $\%$ \\
$08-07$ & $14-07$ & 7 & 197 & 5 & 19 \\
$15-07$ & $21-07$ & 7 & 198 & 5 & 19 \\
$22-07$ & $28-07$ & 14 & 198 & 5 & 19 \\
$01-07$ & $14-07$ & 14 & 802 & 10 & 19 \\
$15-07$ & $28-07$ & 14 & 817 & 10 & 36 \\
$01-07$ & $21-07$ & 21 & 1861 & 16 & 37 \\
$01-07$ & $28-07$ & 28 & 3444 & 24 & 58 \\
$01-07$ & $31-07$ & 31 & 4307 & 28 & 86 \\
\hline VR = valor relativo, estimado em função da TAC de 31 dias. & & 100 \\
\hline
\end{tabular}

O fotoperíodo influencia o acúmulo de forragem (Tabela 5 e Figura 1). O efeito dessa variável está mais relacionado com a relação entre o Nf/Ni, que com o fotoperíodo em si. Isto se deve ao fato de fotoperíodos crescentes $(\mathrm{Nf} / \mathrm{Ni}>1)$ disponibilizam mais unidades fototérmicas (energia) para o sistema que quando esta relação é decrescente, levando-se em conta o mesmo período de tempo. Por esse motivo, se não houvesse efeito da temperatura, o crescimento das plantas seria crescente de agosto a dezembro e decrescente de janeiro a julho. 
Tabela 5. Estimativa do efeito do fotoperíodo sobre a taxa nédia diária de acúmulo de forragem (TAF) utilizando o modelo de unidades fototérmicas (UF), em Piracicaba-SP

\begin{tabular}{cccccccc}
\hline Mês & Dias & GD & Ni & NF & NF/Ni & UF & TAF \\
\hline Janeiro & 31 & 12,00 & 13,31 & 12,97 & 0,97 & 15368 & $\mathrm{~kg} \mathrm{ha}^{-1}$ dia $^{-1}$ \\
Fevereiro & 28 & 12,00 & 12,96 & 12,45 & 0,96 & 11766 & 115 \\
Março & 31 & 12,00 & 12,43 & 11,78 & 0,95 & 13527 & 113 \\
Abril & 30 & 12,00 & 11,76 & 11,17 & 0,95 & 12831 & 110 \\
Maio & 31 & 12,00 & 11,16 & 10,74 & 0,96 & 14528 & 123 \\
Junho & 30 & 12,00 & 10,73 & 10,67 & 0,99 & 15779 & 140 \\
Julho & 31 & 12,00 & 10,68 & 11,00 & 1,03 & 19909 & 174 \\
Agosto & 31 & 12,00 & 11,01 & 11,58 & 1,05 & 22056 & 192 \\
Setembro & 30 & 12,00 & 11,60 & 12,23 & 1,05 & 20884 & 189 \\
Outubro & 31 & 12,00 & 12,25 & 12,85 & 1,05 & 21819 & 190 \\
Novembro & 30 & 12,00 & 12,87 & 13,26 & 1,03 & 18680 & 169 \\
Dezembro & 31 & 12,00 & 13,26 & 13,31 & 1,00 & 17604 & 154 \\
\hline Ni = fotoperíodo inicial, NF = fotoperíodo final, UF = unidade fototérmica e TAF= taxa média diária de \\
\multicolumn{7}{c}{} \\
acúmulo de forragem
\end{tabular}

Os resultados estimados pelo modelo demonstram que temperaturas máximas superiores a 30 (Tabela 6 e Figura 1), provocam a redução na taxa média diária de aqcúmulo de forragem. Além disso, no período de maio a julho, quando as temperaturas média e mínima estão próximas da $\mathrm{T}_{\mathrm{B}}$ registraram-se as menores taxas de acúmulo de forragem. Possivelmente isto é resultado de efeitos independentes entre a temperatura noturna e diurna conforme relatou YIN et al. (1995), trabalhando com modelos de grausdia em Manihot esculenta Crantz e Oryza sativa L. Uma outra razão isto é o fato das temperaturas médias e mínimas seram próximas da temperatura base inferior, sob aqual o crescimento da planta cessa ou é insignificante (McWILLIAM, 1978). 
Tabela 6. Estimativa do efeito da temperatura média do ar (T) sobre a taxa média de acúmulo de forragem (TAF) utilizando o modelo de unidades fototérmicas (UF), em Piracicaba-SP

\begin{tabular}{ccccccccc}
\hline Mês & Tmin & Tmax & T & Dias & GD & NF/Ni & UF & TAF \\
\hline Janeiro & 20 & 31 & 24 & 31 & 7,22 & 1,00 & 6270 & $\mathrm{~kg} \mathrm{ha}^{-1}$ dia $^{-1}$ \\
Fevereiro & 20 & 31 & 24 & 28 & 7,70 & 1,00 & 5818 & 44 \\
Março & 19 & 31 & 24 & 31 & 9,26 & 1,00 & 10297 & 80 \\
Abril & 17 & 30 & 23 & 30 & 9,83 & 1,00 & 10866 & 89 \\
Maio & 13 & 25 & 18 & 31 & 5,45 & 1,00 & 3570 & 22 \\
Junho & 12 & 25 & 18 & 30 & 4,59 & 1,00 & 2366 & 15 \\
Julho & 11 & 26 & 18 & 31 & 4,92 & 1,00 & 2910 & 18 \\
Agosto & 12 & 27 & 20 & 31 & 6,58 & 1,00 & 5198 & 35 \\
Setembro & 15 & 28 & 21 & 30 & 7,80 & 1,00 & 6849 & 50 \\
Outubro & 16 & 29 & 22 & 31 & 9,08 & 1,00 & 9908 & 77 \\
Novembro & 19 & 30 & 24 & 30 & 10,62 & 1,00 & 12697 & 108 \\
Dezembro & 19 & 29 & 23 & 31 & 9,98 & 1,00 & 11962 & 97 \\
Tmin = média das temperaturas mínimas do ar, Tmax = média das temperaturas máximas do ar, T = média \\
das temperaturas médias do ar, Dias = número de dias de crescimento, GD = Graus - dia, UF = unidade \\
fototérmica, TAF = taxa média diária de acúmulo de forragem
\end{tabular}

Embora a temperatura seja o maior fator determinante da estacionalidade do acúmulo de forragem, os efeitos desta são modificados pela ação do fotoperíodo (Figura 1). Esse efeito integrado entre a temperatura e o fotoperíodo sobre o crescimento das plantas foi relatado por HODGES (1990) e por VILLA NOVA et al. (1999). Além disso, reforça afirmação de BONHOMME (2000) de que outros fatores além da temperatura afetam o crescimento das plantas. 


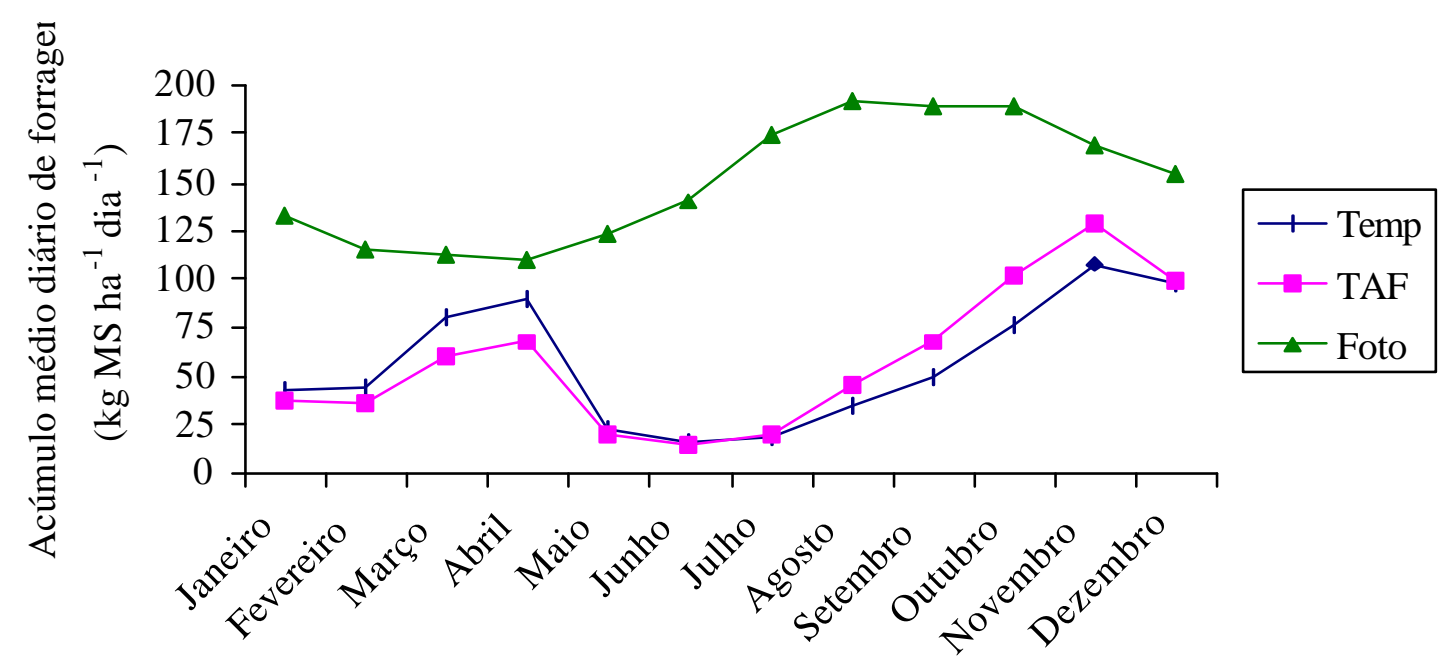

Meses do ano

Figura 1 - Efeito do fotoperíodo (Foto), da temperatura (Temp) e da unidade fototérmica sobre a taxa média diária de acúmulo de forragem(TAF)

Este modelo poderá ser utilizado para estimar o acúmulo de forragem nas pastagens irrigadas, desde não existam limitações físicas e de fertilidade de solo e os fatores de variação sejam unicamente fotoperíodo e temperatura. Com isso pode-se estimar o acúmulo de forragem presente na pastagem e assim traçar estratégias de utilização desta. Uma outra aplicação do modelo é no planejamento de sistemas de produção de forragem suplementar, por exemplo feno. Nesse caso o usuário poderá estimar o acúmulo de forragem e determinar o momento mais adequado sua colheita e armazenamento.

Para a utilização do modelo de UF em pastagens cultivadas sob condições não irrigadas, deve-se incorporar ao mesmo ferramentas matemáticas que permitam 
incorporar o risco de acúmulo de forragem menor que o esperado, provocado por déficite hídrico.

\subsection{Conclusões}

O Modelo de UF proposto é adequado para estimar a produção de Cynodon spp. desde que os fatores de variação sejam unicamente fotoperíodo e temperatura. No futuro mais variáveis, por exemplo, que incorporem os efeitos de fertilizade e umidade do solo sobre o acumulo de forragem deverão ser incorporadas ao modelo a fim de melhorar a exatidão das suas estimativas. 


\section{AVAliaçÃo de MOdelos MATEMÁticos PARA ESTIMAR O CONSUMO DE FORRAGEM E O DESEMPENHO ANIMAL EM PASTAGENS}

\section{Resumo}

Nos sistemas de produção de ruminantes em pastagens o desempenho animal é função do valor nutritivo e do consumo de forragem, além da eficiência de conversão dessa em produto animal. O consumo é modulado por características da pastagem (e.g., estrutura, oferta e digestibilidade da forragem), dos animais (e.g. espécie, estado fisiológico e requerimentos nutricionais) e edafoclimáticas da região (temperatura e umidade). Este trabalho teve por objetivos estudar o efeito da oferta de forragem verde (folhas + hastes) e a oferta de folhas sobre o consumo real de forragem e o desempenho dos animais em pastagem de gramíneas tropicais. O modelo superestimou o consumo de forragem real pelos animais quando resolvido utilizando-se a oferta de matéria verde (haste+folhas). Quando, entretanto, o modelo foi resolvido com substituição da oferta de matéria verde por folhas verdes os resultados estimados e medidos foram iguais. O modelo proposto para estimar o desempenho dos animais deve ser reparametrizado a fim de melhorar a exatidão das suas estimativas quando a simulação usa dados de sistemas de produção de rumintantes em pastagens de clima tropical. A utilização de modelos para estimar o consumo de forragem e o desempenho animal poderá orientar a condução de trabalhos 
de pesquisa e ampliar a quantidade de informações disponíveis sobre essas variáveis nos sistemas de produção de ruminantes em pastagem. Essas informações, se organizadas, poderão ser utilizadas para o desenvolvimento e/ou utilização de modelos mais mecanísticos (explicativos) do ecossistema da pastagem, que permitam o melhor entendimento das respostas do mesmo a ações de manejo.

\title{
EVALUATING MATHEMATICAL MODELS USED TO PREDICT FORAGE INTAKE AND ANIMAL PERFORMANCE ON PASTURE
}

\begin{abstract}
In ruminant production systems animal performance is a function of both forage intake and nutritive value as well as the efficiency with which the forage is converted into animal product. Intake is also regulated by characteristics of the pasture (e.g., sward structure, forage allowance and digestibility), animals (e.g., species, physiological cond ition, nutritional requirements), and of the environment (e.g., temperature, humidity). The objectives of the present research were to assess the effect of green forage allowance (leaf + stem) and of green leaf allowance on forage intake and animal performance from tropical grass pastures using modeling. Modeling overestimated forage intake when using total green dry matter (leaf + stem), but was accurate when green leaf allowance substituted for total green forage allowance. Choice of model parameters must be improved to increase the prediction accuracy of animal performance predictions from tropical pastures. The use of modeling in predicting forage intake and animal performance may optimize research efforts and resource use as well as establish
\end{abstract}


guidelines for the generation of datasets concerning forage and animal responses from grazed pastures in the tropics. Such information will be useful in the development of mechanistic (explanatory) models of grazed pasture ecosystems which will allow for a better understanding of the responses of these systems to management.

\subsection{Introdução}

Nos sistemas de produção de ruminantes em pastagens o desempenho animal é função do consumo de forragem e da eficiência de conversão dessa em carne, leite, lã entre outros produtos. Essa propriedade (o consumo) é o resultado da interação entre características da pastagem (e.g., estrutura, oferta e digestibilidade da forragem), dos animais (e.g. espécie, estado fisiológico e requerimentos nutricionais) e edafoclimáticas da região (GORDON e LASCANO, 1993).

A oferta de forragem (OF) descreve a relação instantânea entre a massa de forragem e o peso vivo total dos animais presentes numa área de pastagem (FGTC, 1992). A OF pode ser uma das ferramentas utilizadas para manejar pastagens, visto que pode ser controlada pelo manejador, por exemplo, com o ajuste da taxa de lotação. A OF, a composição morfológica da forragem e o arranjo estrutural do dossel são características que influenciam a seleção, a massa de forragem apreendida por bocado e o consumo total do animal (STTOBS 1973a; STTOBS, 1973b; NEWMAN et al. 1995; GORDON e LASCANO, 1993). Isto se deve ao fato dos animais selecionarem preferencialmente folhas verdes a hastes e material morto (STOBBS, 1975). Além disso, nas gramíneas de clima tropical $\left(\mathrm{C}_{4}\right)$ o arranjo estrutural das folhas e/ou a densidade volumétrica dificultam a apreensão e o corte da forragem pelo animais (STOBBS, 
1973a). Por esses motivos, os animais precisam investir mais tempo à manipulação e na apreensão da forragem, com isso aumentam o período de pastejo e reduzem as horas de ócio e/ou ruminação (WOODWARD, 1997). Esse é um dos mecanismos utilizados pelos animais para manter o nível de consumo de forragem (GORDON e LASCANO, 1993). Todavia, isso tem um custo (energia gasta no pastejo e na ruminação da forragem consumida) (SCA, 1990) e pode causar desconforto ao animal e leva-lo a interromper o pastejo antes da saciedade física ou metabólica, reduzindo o consumo total diário de forragem. Possivelmente, o animal procura neste ajuste otimizar o consumo líquido de energia para mantença, produção e reprodução.

Assim, este trabalho teve por objetivos estudar o efeito da oferta de forragem verde (folhas + hastes) e a oferta de folhas sobre o consumo real de forragem e o desempenho dos animais em pastagem de gramíneas tropicais. Para isso foram utilizados modelos matemáticos que estimam o consumo de forragem e o desempenho dos animais em sistemas de produção de ruminantes em pastagens.

\subsection{Material e métodos}

\subsubsection{Descrição dos modelos utilizados}

O consumo potencial $\left(\mathrm{I}_{\max }\right)$ dos animais foi determinado utilizando o modelo proposto por FREER (1997), equação 1.

$$
\mathrm{I}_{\max }=0,4 * P R * X *(1,7-X) * \mathrm{~L} * \mathrm{~T} * \mathrm{D}
$$

Onde,

$\mathrm{I}_{\max }=$ consumo potencial do animais, 
PR = peso de referência do animal adulto,

$\mathrm{X}=$ tamanho relativo do animal (calculado pela divisão entre o peso do animal (PA) a hora da simulação e o PR),

$\mathrm{L}=$ fator de correção para animais em lactação $(\mathrm{L}=1)$,

$\mathrm{T}=$ fator de correção para a temperatura ambiente $(\mathrm{T}=1)$,

$\mathrm{D}=$ fator de correção para animais lactentes $(\mathrm{L}=1)$,

O consumo de forragem (CF) dos animais foi estimado utilizando-se o modelo proposto por McCALL (1984). De acordo com McCALL (1984) o consumo dos animais em pastagens é o resultado da multiplicação do Inax pelo fator de correção (M). O fator M é um valor entre 0 e 1 , calculado em função da oferta e digestibilidade da forragem (equações 2 e 3$)$.

$$
\begin{aligned}
& \mathrm{A}=1-1,42 * \operatorname{EXP}(-0,00198 * \mathrm{MVS}) \\
& \mathrm{M}=\mathrm{A} * \operatorname{EXP}(-1,016 * \operatorname{EXP}(-1,0308 * \mathrm{OFP}))
\end{aligned}
$$

Onde,

EXP $=$ Exponencial (2,7182),

MVS = Massa Verde Seca $(\mathrm{kg} / \mathrm{ha})$

$\mathrm{OFP}=$ oferta de forragem dividido pelo consumo potencial do animal.

Após o cálculo do CF de forragem, o modelo foi novamente rodado com duas modificações, a MVS foi substituída pela massa de folhas verdes (MFS, $\mathrm{kg} \mathrm{MS} \mathrm{ha-1)} \mathrm{e}$ a OFP pela oferta de folhas. Após as modificações o modelo para estimar o CF dos animais foi novamente rodado. 
Os requerimentos para mantença (equações 4,5 e 6) e ganho de peso (equações 7, 8, 9 e 10) dos animais foram estimadas utilizado-se o modelo proposto pelo SCA (1990):

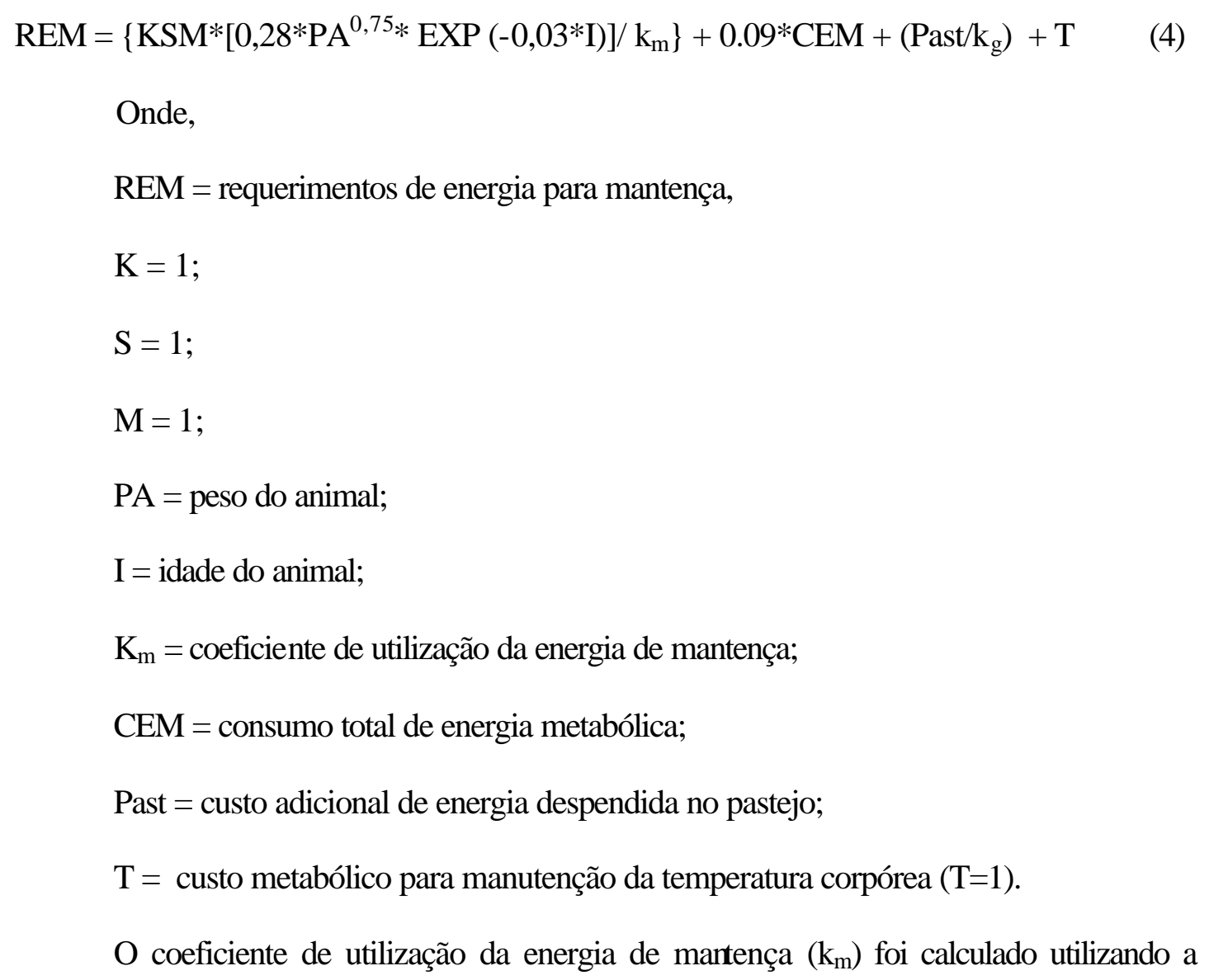
equação 5 .

$$
\mathrm{k}_{\mathrm{m}}=0,02 \mathrm{CE}+0,5
$$

Onde,

$\mathrm{CE}=$ concentração energética $(\mathrm{kg}$ de energia metabolizável $/ \mathrm{kg}$ de matéria seca) da dieta consumida pelo animal.

O custo adicional de energia despendida no pastejo (Past) foi calculado utilizando-se a equação 6. 
Past $=\left\{\left[0,05 * \mathrm{CMS}^{*}(0,9-\mathrm{DIG})\right]+[0,05 * \mathrm{Re} \mathrm{l} /(\mathrm{OF}+3)]\right\}^{*} \mathrm{PA}$

Onde,

CMS = consumo de matéria seca;

$\mathrm{DIG}=$ digestibilidade da forragem (em decimal);

Rel = fator de correção para o relevo do terreno $(\operatorname{Rel}=1)$;

$\mathrm{OF}=$ oferta de forragem $\left(\mathrm{kg} \mathrm{MS} \cdot \mathrm{ha}^{-1} / \mathrm{kg} \mathrm{PV} \cdot \mathrm{ha}^{-1}\right)$;

$\mathrm{PA}=$ peso do animal.

O coeficiente de utilização de energia para ganho foi calculado utilizando-se a equação 7.

$\mathrm{K}_{\mathrm{g}}=0,043 \mathrm{CE}$

Onde ,

$\mathrm{K}_{\mathrm{g}}=$ coeficiente de utilização de energia para ganho,

$\mathrm{CE}=$ concentração energética da dieta consumida ( $\mathrm{Mj} / \mathrm{kg} \mathrm{MS})$.

O ganho de peso vivo (GPV) foi calculado utilizando-se a equação 8 .

$\mathrm{GPV}=\mathrm{ERG} /\left(\mathrm{GP}_{\text {Vazio }} * 0,92\right)$

Onde,

GPV = ganho de peso vivo;

$\mathrm{ERG}=$ energia retida para ganho;

$\mathrm{GP}_{\text {vazio }}=$ ganho de peso vazio

O ganho de peso vazio foi calculado utilizando-se a equação 9.

$\mathrm{GP}_{\text {vazio }}=6,7+\mathrm{R}+(20,3-\mathrm{R}) /\left[1+\operatorname{EXP}\left(-6^{*}(\mathrm{X}-0,4)\right)\right]$ 
Onde,

$\mathrm{R}=$ ajuste para ganho ou perda de peso;

$\mathrm{X}=$ tamanho relativo do animal

$\mathrm{O}$ valor de $\mathrm{R}$ foi calculado utilizando-se a equação 10 .

$\mathrm{R}=2 *\left[\left(\mathrm{k}_{\mathrm{g}} * \mathrm{ERG} / \mathrm{REM}\right)-1\right) \quad(10)$

Onde,

$\mathrm{k}_{\mathrm{g}}=$ coeficiente de utilização de energia para ganho,

$\mathrm{ERG}=$ Energia retida para ganho,

$\mathrm{REM}=$ requerimentos de energia para mantença.

\subsubsection{Descrição do cenário simulado}

Utilizourse os resultados publicados por CARNEVALLI (1999), que trabalhou com pastagens de Cynodon spp. mantidas em mantida em condição constante de altura $(5,10,15$ e $20 \mathrm{~cm})$ de agosto de 1998 a março de 1999 . O método de pastejo utilizado foi lotação contínua, e o pastejo realizado por ovinos de corte. A taxa de lotação e peso médio dos animais utilizados para alimentar o modelo foram os mesmos medidos e publicados por CARNEVALLI (1999), e os valores de oferta de matéria seca verde, de folhas, foram calculadas utilizando a metodologia proposta por SOLLENBERGER e MOORE (1997) (tabela 1). 
Tabela 1. Massa verde seca (MVS), massa de folhas verdes seca (MFV) calculadas utilizando os dados publicados por CARNEVALLI (1999) e taxa de lotação (TL) calculada utilizando a metodologia proposta por SOLLENBERGER e MOORE (1997) em pastagens de Cynodon spp. mantidas em lotação contínua com ovinos e altura constante de $5 \mathrm{~cm}$

\begin{tabular}{cccc}
\hline Mês & MVS & MFV & TL \\
\hline Ago & 1251 & 423 & 1342 \\
Set & 1294 & 315 & 1563 \\
Out & 1532 & 506 & 1615 \\
Nov & 1983 & 578 & 1792 \\
Dez & 1656 & 396 & 1937 \\
Jan & 1322 & 361 & 2252 \\
Fev & 1112 & 320 & 1804 \\
Mar & 1543 & 489 & 1375 \\
Média & 1462 & 424 & 1710
\end{tabular}

Tabela 2. Massa verde seca (MVS), massa de folhas verdes seca (MFV) calculadas utilizando os dados publicados por CARNEVALLI (1999) e taxa de lotação (TL) calculada utilizando a metodologia proposta por SOLLENBERGER e MOORE (1997) em pastagens de Cynodon spp. mantidas em lotação contínua com ovinos e altura constante de $10 \mathrm{~cm}$

\begin{tabular}{cccc}
\hline Mês & MSV & MFV & TL \\
\hline Ago & 2344 & 857 & 767 \\
Set & 1894 & 415 & 1405 \\
Out & 2422 & 864 & 1420 \\
Nov & 2733 & 701 & 1361 \\
Dez & 2443 & 621 & 1409 \\
Jan & 1965 & 661 & 1611 \\
Fev & 1963 & 653 & 1316 \\
Mar & 2354 & 820 & 1700 \\
Média & 2265 & 699 & 1373 \\
\hline
\end{tabular}


Tabela 3. Massa verde seca (MVS), massa de folhas verdes seca (MFV) calculadas utilizando os dados publicados por CARNEVALLI (1999) e taxa de lotação (TL) calculada utilizando a metodologia proposta por SOLLENBERGER e MOORE (1997) em pastagens de Cynodon spp. mantidas em lotação contínua com ovinos e altura constante de $15 \mathrm{~cm}$

\begin{tabular}{cccc}
\hline Mês & MSV & MFV & TL \\
\hline Ago & 2749 & 924 & 1100 \\
Set & 2398 & 603 & 1520 \\
Out & 2944 & 1032 & 1277 \\
Nov & 3370 & 756 & 1084 \\
Dez & 3158 & 758 & 1479 \\
Jan & 2571 & 793 & 1586 \\
Fev & 2733 & 799 & 1369 \\
Mar & 2868 & 1035 & 1721 \\
Média & 2849 & 838 & 1392
\end{tabular}

Tabela 4. Massa verde seca (MVS), massa de folhas verdes seca (MFV) calculadas utilizando os dados publicados por CARNEVALLI (1999) e taxa de lotação (TL) calculada utilizando a metodologia proposta por SOLLENBERGER e MOORE (1997) em pastagens de Cynodon spp. mantidas em lotação contínua com ovinos e altura constante de $20 \mathrm{~cm}$

\begin{tabular}{cccc}
\hline Mês & MSV & MFV & TL \\
\hline Ago & 3635 & 1253 & 781 \\
Set & 3239 & 889 & 1026 \\
Out & 3623 & 1280 & 1059 \\
Nov & 3954 & 904 & 932 \\
Dez & 3605 & 841 & 1100 \\
Jan & 3191 & 961 & 1573 \\
Fev & 3450 & 951 & 2037 \\
Mar & 4216 & 1068 & 1381 \\
Média & 3614 & 1019 & 1236 \\
\hline
\end{tabular}




\subsubsection{Análise estatística}

Os resultados de consumo de matéria seca ( $\mathrm{kg} / \mathrm{animal} / \mathrm{dia})$ e ganho de peso (kg/animal/dia) estimados pelo modelo foram comparados aos medidos por CARNEVALLI (1999) utilizando teste "t”. A análise estatística foi realizada utilizandose o procedimento Proc GLM do pacote estatístico SAS ${ }^{\circledR}$, Statistical Analisyss System, (SAS INSTITUTE, 1988).

\subsection{Resultados e discussão}

O modelo proposto por McCALL (1984) superestimou o consumo real dos animais, quando resolvido utilizando-se a oferta de matéria verde (haste+folhas) (Tabelas 5, 6, 7 e 8). Todavia, os resultados calculados por esse modelo, quando resolvido com as modificações propostas neste trabalho (substituição da oferta de matéria verde por folhas verdes) foram estatisticamente iguais aos estimados por CARNEVALLI (1999) para as condições de pastagem simuladas $(5,10,15$ e 20 cm). 
Tabela 5. Oferta de matéria verde seca (OMVS), oferta de folhas verdes (OFV), consumo de forragem (CMV) estimado em função da OMVS, consumo de forragem (Cfolha) estimado em função da OFV e consumo estimado (Real) por CARNEVALLI (1999) em pastagens de Cynodon spp. mantidas em sistema de lotação contínua com ovinos e altura constante de $5 \mathrm{~cm}$ de agosto/setembro de 1998 e dezembro/1998 a março/1999

\begin{tabular}{cccccc}
\hline Mês & OMVS & OFV & CMV & Cfolha & Real \\
\hline Ago & 0,93 & 0,32 & 0,95 & 0,49 & 0,42 \\
Nov & 0,83 & 0,20 & 0,75 & 0,36 & 0,15 \\
Dez & 0,85 & 0,20 & 0,47 & 0,28 & 0,17 \\
Jan & 0,59 & 0,16 & 0,47 & 0,29 & 0,33 \\
Fev & 0,62 & 0,18 & 0,42 & 0,23 & 0,34 \\
Mar & 1,12 & 0,36 & 0,76 & 0,38 & 0,43 \\
Média & 0,82 & 0,24 & $0,64^{\text {a }}$ & $0,34^{\mathrm{b}}$ & $0,31{ }^{\mathrm{b}}$ \\
\multicolumn{4}{l}{ Letras iguais indicam que não existe diferença } & $(\mathrm{P}<0,05)$ pelo teste " $\mathrm{t}$ "
\end{tabular}

OMVS e OFV calculadas utilizando o método proposto por SOLLENBERGER e MOORE (1997)

Consumo de forragem calculado utilizando o método proposto por McCALL (1984) 
Tabela 6. Oferta de matéria verde seca (OMVS), oferta de folhas verdes (OFV), consumo de forragem (CMV) estimado em função da OMVS, consumo de forragem (Cfolha) estimado em função da FV e consumo estimado (Real) por CARNEVALLI (1999) em pastagens de Cynodon spp. mantidas em sistema de lotação contínua com ovinos e altura constante de $10 \mathrm{~cm}$ de agosto/1998 a março/1999

\begin{tabular}{cccccc}
\hline Mês & OMVS & OFV & CMV & Cfolha & Real \\
\hline Ago & 3,06 & 1,12 & ----- kg MS animal $^{-1}$ & dia $^{-1}------$ \\
Set & 1,35 & 0,30 & 0,99 & 0,62 & 0,53 \\
Out & 1,71 & 0,61 & 1,11 & 0,45 & 0,49 \\
Nov & 2,01 & 0,52 & 0,86 & 0,39 & 0,43 \\
Dez & 1,73 & 0,44 & 0,65 & 0,31 & 0,33 \\
Jan & 1,22 & 0,41 & 0,67 & 0,34 & 0,42 \\
Fev & 1,49 & 0,50 & 0,73 & 0,36 & 0,36 \\
Mar & 1,38 & 0,48 & 0,87 & 0,42 & 0,50 \\
Média & 1,74 & 0,55 & $0,88^{\text {a }}$ & $0,43^{\mathrm{b}}$ & $0,41^{\mathrm{b}}$ \\
\hline Letras iguais indicam que não existe diferença $(\mathrm{P}<0,05)$ pelo teste " $\mathrm{t}$ "
\end{tabular}

OMVS e OFV calculadas utilizando o método proposto por SOLLENBERGER e MOORE (1997)

Consumo de forragem calculado utilizando o método proposto por McCALL (1984) 
Tabela 7. Oferta de matéria verde seca (OMVS), oferta de folhas verdes (OFV), consumo de forragem (CMV) estimado em função da OMVS, consumo de forragem (Cfolha) estimado em função da FV e consumo estimado (Real) por CARNEVALLI (1999) em pastagens de Cynodon spp. mantidas em sistema de lotação contínua com ovinos e altura constante de $15 \mathrm{~cm}$ de agosto/1998 a março/1999

\begin{tabular}{|c|c|c|c|c|c|c|}
\hline Altura & Mês & OMVS & FV & CMV & Cfolha & Estimado \\
\hline & & & & \multicolumn{3}{|c|}{------kg MS animal ${ }^{-1}$ dia $^{-1}------$} \\
\hline $15 \mathrm{~cm}$ & Ago & 2,50 & 0,84 & 1,15 & 0,61 & 0,56 \\
\hline $15 \mathrm{~cm}$ & Set & 1,58 & 0,40 & 1,13 & 0,51 & 0,29 \\
\hline $15 \mathrm{~cm}$ & Out & 2,31 & 0,81 & 1,25 & 0,66 & 0,30 \\
\hline $15 \mathrm{~cm}$ & Nov & 3,11 & 0,70 & 1,07 & 0,52 & 0,26 \\
\hline $15 \mathrm{~cm}$ & Dez & 2,14 & 0,51 & 0,79 & 0,36 & 0,33 \\
\hline $15 \mathrm{~cm}$ & Jan & 1,62 & 0,50 & 0,77 & 0,37 & 0,47 \\
\hline $15 \mathrm{~cm}$ & Fev & 2,00 & 0,58 & 0,74 & 0,36 & 0,39 \\
\hline \multirow{2}{*}{$15 \mathrm{~cm}$} & Mar & 1,67 & 0,60 & 0,91 & 0,44 & 0,50 \\
\hline & Média & 2,11 & 0,62 & $0,98^{\mathrm{a}}$ & $0,48^{b}$ & $0,39^{\mathrm{b}}$ \\
\hline
\end{tabular}

OMVS e OFV calculadas utilizando o método proposto por SOLLENBERGER e MOORE (1997)

Consumo de forragem calculado utilizando o método proposto por McCALL (1984) 
Tabela 8. Oferta de matéria verde seca (OMVS), oferta de folhas verdes (OFV), consumo de forragem (CMV) estimado em função da OMVS, consumo de forragem (Cfolha) estimado em função da FV e consumo estimado (Real) por CARNEVALLI (1999) em pastagens de Cynodon spp. mantidas em sistema de lotação contínua com ovinos e altura constante de $20 \mathrm{~cm}$ de agosto/1998 a março/1999

\begin{tabular}{cccccc}
\hline Mês & OMVS & FV & CMV & Cfolha & Estimado \\
\hline Ago & 4,66 & 1,60 & 0,98 & 0,58 & 0,51 \\
Set & 3,16 & 0,87 & 1,09 & 0,52 & 0,47 \\
Out & 3,42 & 1,21 & 1,17 & 0,67 & 0,39 \\
Nov & 4,24 & 0,97 & 1,01 & 0,53 & 0,34 \\
Dez & 3,28 & 0,76 & 0,92 & 0,42 & 0,40 \\
Jan & 2,03 & 0,61 & 0,90 & 0,43 & 0,49 \\
Fev & 1,69 & 0,47 & 0,90 & 0,43 & 0,32 \\
Mar & 3,05 & 0,77 & 1,11 & 0,57 & 0,45 \\
Média & 3,19 & 0,91 & $1,01^{\text {a }}$ & $0,52^{\mathrm{b}}$ & $0,42^{\mathrm{b}}$ \\
\hline Letras iguais indicam que não existe diferença $(\mathrm{P}<0,05)$ pelo teste "t"
\end{tabular}

OMVS e OFV calculadas utilizando o método proposto por SOLLENBERGER e MOORE (1997)

Consumo de forragem calculado utilizando o método proposto por McCALL (1984)

Em pastagens de Cynodon spp. o alongamento de haste ocorre mesmo quando as plantas estão no estado vegetativo, tornando significativa a participação desse componente morfológico na massa de forragem (PINTO, 2000). Uma vez que os animais, sempre que conseguem, selecionam na sua dieta maior quantidade de folhas verdes que de outros componentes (hastes e material morto) presentes na pastagem (MARASCHIN, 2000), o acúmulo de hastes no pasto dificulta o processo de seleção e apreensão de forragem pelos animais. Esses, buscam, durante o pastejo, selecionar a 
maior quantidade (massa) e com o melhor valor nutricional (digestibilidade) possível, a fim de atender seus requerimentos nutricionais de mantença e produção. É essa característica (a seletividade) que explica por que a qualidade da dieta selecionada pelos animais é melhor que a da forragem ofertada (McCALL, 1984). Esse processo de seleção de espécies e tecidos, resulta em gasto de tempo no processo de manipulação, apreensão e corte da forragem (PARSONS et al., 1994). Todavia, é esse mecanismo que permite ao animal otimizar o consumo de energia para manutenção e produção, bem como explica por que às vezes ele para de consumir forragem antes de atingir a saciedade física ou metabólica (STTOBS, 1975; THORNLEY et al., 1994). Assim, utilizando-se como variável de entrada do modelo a oferta de folhas verdes, o usuário está representando uma condição (decisão) mais próxima da estratégia utilizada pelo animal no pastejo.

Uma outra característica do dossel, a sua estrutura, também afeta o consumo de forragem dos animais. O arranjo estrutural (tridimensional) dos componentes do dossel afeta a massa de forragem apreendida por volume de bocado e consequentemente o consumo total de forragem (WOODWARD, 1997). Esse efeito da estrutura (especialmente densidade volumétrica e altura) associado à composição morfológica (relação folha/haste, massa de haste e de material morto) são os fatores que tem maior influência na massa de forragem apreendida por bocado (STOBBS, 1973a; STOBBS, 1973b; WOODWARD, 1997). Além disso, o aumento no tempo de manipulação da forragem resulta na diminuição do consumo de total do animal. A associação de características do animal (seleção) e do pasto (estrutura e composição morfológica do 
dossel) é uma das razões porque o consumo real de forragem e o desempenho dos animais na pastagem são menores do que aquele que o potencial genético pressupõe.

O modelo SCA subestimou o desempenho animal, exceto para mantidos a $5 \mathrm{~cm}$. Possivelmente isso se deve à superestimava do custo de pastejo, de ruminação da forragem consumida e/ou da subestimava do valor nutricional (digestibilidade evalor nutritivo) da dieta selecionada. $\mathrm{O}$ custo do pastejo estima o gasto energético que o animal tem ao pastejar, decorrentes, por exemplo, da ação de andar pela pastagem, manipular, apreender, e colher a forragem. Por sua vez o custo de ruminação reflete o tempo e energia gasto pelo animal para ruminar e digerir a forragem consumida.

Além desses dois fatores (custo do pastejo e de ruminação), o desempenho dos animais também é afetado pela qualidade da dieta selecionada. Nos sistemas de produção de ruminantes em pastagens, os animais selecionam uma dieta de melhor qualidade (digestibilidade) que a ofertada (McCALL, 1984). A capacidade de seleção está relacionada com a oferta de forragem e o hábito de pastejo de cada espécie animal (McCALL, 1984). Por estes motivos, o desenvolvimento de modelos para estimar consumo e desempenho de ruminantes vem procurando adotar uma abordagem mecanista para explicar o consumo de forragem e o desempenho animal nos sistemas de produção em pastagem (WOODWARD, 1997; BARIONI, 2002). 
Tabela 9. Ganho de peso estimado pelo modelo SCA em função da oferta de matéria verde (GPCMV), da oferta de folhas verdes (Gpfolha) e medido por CARNEVALLI (1999) em pastagens de Cynodon spp. mantidas em sistema de lotação contínua com ovinos e altura constante de $20 \mathrm{~cm}$ de agosto/1998 a março/1999

\begin{tabular}{cccc}
\hline Altura & GPCMV & Gpfolha & Medido \\
\hline $\mathrm{cm}$ & $--\mathrm{animal}^{-1}$ dia $^{-1}-1^{\mathrm{a}}$ & $0,00^{\mathrm{a}}$ & $0,01^{\mathrm{a}}$ \\
5 & $0,01^{\mathrm{a}}$ & $0,00^{\mathrm{a}}$ & $0,04^{\mathrm{b}}$ \\
10 & $0,01^{\mathrm{a}}$ & $0,00^{\mathrm{a}}$ & $0,0^{\mathrm{b}}$ \\
15 & $0,01^{\mathrm{a}}$ & $0,00^{\mathrm{a}}$ & $0,04^{\mathrm{b}}$ \\
\hline
\end{tabular}

Letras iguais indicam que não existe diferença estatística significativa $(\mathrm{P}<0,05)$ pelo teste $\mathrm{t}$

Assim, o conhecimento e o entendimento dos fatores comportamentais relacionados ao consumo e à qualidade da dieta selecionada pelos animais poderá aumentar a exatidão das estimativas dos modelos de simulação dos sistemas de produção de animais em pastagens (DEMMENT, et al., 1995). Isso pode resultar no desenvolvimento de ferramentas computacionais que permitiram aos usuários dos modelos otimizar o uso das pastagens e com isso ter maior controle sobre o processo de produção.

\subsection{Conclusões}

O modelo proposto por McCALL (1984) estima corretamente o consumo de forragem de Cynodon spp. por ovinos, desde que o usuário substitua a oferta de matéria verde (folhasthaste) pela a oferta de folhas verdes. Entretanto, o modelo do SCA deverá ser reparametrizado a fim de melhorar a exatidão das suas estimativa quando rodado 
com dados de resultados de sistemas de produção de ruminantes em pastagens de clima tropical.

A utilização desses modelos (McCALL e SCA) para orientar a condução de trabalhos de pesquisa poderá ampliar a quantidade de informações disponíveis sobre consumo de forragem e desempenho animal nos sistemas de produção de ruminantes em pastagens. Essas informações poderão ser utilizadas para o desenvolvimento e/ou utilização de modelos mais mecanistas (explicativos) do ecossistema da pastagem, que permitam o melhor entendimento das respostas do mesmo a ações de manejo. 


\section{CONCLUSÕES}

A utilização de modelos matemáticos pode ser uma ferramenta útil no processo de tomada de decisão em sistemas agropecuários, bem como no ensino/pesquisa. Todavia, deve-se avaliar e validar os mesmos sob pena de se produzirem resultados que não condizem com a realidade. Idealmente, os modelos devem ser o mais simples possível, desde que isto não comprometa a exatidão das estimativas, a fim de minimizar os erros inerentes a coleta de informações (dados de entrada) para rodar o modelo.

No caso específico de sistemas de produção de ruminantes em pastagens, a uniformidade de procedimentos metodológicos para estimar a massa e a composição morfológica de forragem e o cálculo correto da OF é o caminho para que se possa comparar sistemas e desempenho animal em diferentes regiões e anos. Isto ocorre por que na pastagem, o consumo dos animais é resultado da integração entre os requerimentos nutricionais e a seleção imposta pelo animal na pastagem com a oferta, estrutura e digestibilidade da forragem. Além disso, o melhor entendimento da dinâmica da pastagem e do pastejo possibilitará a utilização de modelos mais mecanistas (explicativos) dos fenômenos que ocorrem nestes sistemas. Com isso pode-se integrar os resultados de diversas pesquisas e possivelmente melhorar a capacidade de previsão e a repetibilidade dos resultados destas. 
O modelo de unidades fototérmicas proposto por VILLA NOVA et al. (1983) é capaz de estimar os efeitos do clima (fotoperíodo e temperatura do ar) sobre o acúmulo de forragem ao longo do ano e identificou a temperatura como o principal fator climático causador da estacionalidade na região de Piracicaba - SP. Contudo, este efeito é modificado pelo fotoperíodo, ndicando que a soma térmica (graus-dia), pode não ser o parâmetro mais adequado para se estimar o acúmulo de frragem, especialmente durante as estações outono e primavera, quando a variância das temperaturas médias do ar são maiores e não guardam relação com o fotoperíodo.

A incorporação de mais variáveis para estimar a influência da umidade e fertilidade do solo sobre a produção e a composição morfológica da planta são alternativas que poderão ajudar a melhor descrever o acúmulo de forragem. Este caráter mais mecanísta do modelo permitiria estimar melhor a massa e de folhas verdes na pastagem durante o ano. Este resultado pode auxiliar no planejamento da utilização da pastagem, uma vez que otimizando a massa de folhas em relação a massa total o manejador pode estimar o momento mais adequado para colher a forragem, seja esta por animais ou máquinas.

Uma outra aplicação do modelo da UF, uma vez incorporados os efeitos de umidade e fertilidade do solo sobre o acúmulo, bem como descrever e/ou estimar a composição morfológica da forragem é que os resultados estimados (saídas do modelo) serão dados de entrada para modelos que estimam o consumo de forragem como o proposto por McCALL (1984). Isso permitiria integrar os resultados de várias pesquisas e a construção de um modelo de simulação composto por solo - planta - animal. 
A utilização desses modelos em conjunto poderá orientar a condução de trabalhos de pesquisa, ampliando e integrando as informações disponíveis sobre os diversos componentes do sistema de produção de ruminantes em pastagem. Essas informações poderão ser utilizadas para o desenvolvimento e/ou utilização de modelos mais mecanísticos (explicativos) do ecossistema da pastagem e proporcionando um melhor entendimento das respostas do mesmo à ações de manejo. Com isso, talvez seja possível estabelecer o manejo ótimo para cada situação, minimizando o desperdício de recursos e maximizando a eficiência de produção do sistema. 


\section{REFERÊNCIAS BIBLIOGRÁFICAS:}

ALCANTARA, P. B.; PEDRO JUNIOR., M. J.; DONZELLI, P.L. Zoneamento edafoclimático de plantas forrageiras. In: FAVORETTO, V.; RODRIGUES, L. R. A.; REIS, R. de A. (Ed.). Simpósio sobre Ecossistemas de Pastagens 2, Jaboticabal, 1989. Anais. Jaboticabal:FUNEP,UNESP, 1989. P1-16.

ASSIS, A. G.; BARBOSA, P. F.; SILVA JUNIOR., A G. Modelagem de sistemas para a tomada de decisões na pecuária leiteira. In: REUNIÃO ANUAL DA SOCIEDADE BRASILEIRA DE ZOOTECNIA, 36., Porto Alegre, RS, 1999. Anais. Porto Alegre : SBZ, 1999.p. 297 - 304

BARIONI, L. G. Modelagem dinâmica e otimização metaheurística para apoio à tomada de decisões na recria e engorda de bovinos de corte. Piracicaba, 2002a. 100p. Tese (Doutorado) - Escola Superior de Agricultura "Luiz de Queiroz", Universidade de São Paulo. 
BARIONI, L. G.; VELOSO, R. F.; MARTHA JUNIOR, G. B. MODELOS DE TOMADA DE DECISÃO PARA PRODUTORES DE OVINOS E BOVINOS DE CORTE. In: EVERLING, D. M.; QUADROS, F. L. F. de; VIÉGAS, J.; SANCHES, L. M. B.; GONÇALVES, M. B. F.; LOVATTO, P. A.; RORATO, P. R. N. (Ed.) Modelos para a tomada de decisões na produção de bovinos e ovinos, Santa Maria, 2002. Anais. Santa Maria:UFSM, 2002. p. 05-60.

BARIONI, L.G.; DAKE, C.; PARKER, W.J. Optimizing rotational grazing in sheep management systems. Environment international, v.25, p.819-825, 1999c.

BARRET, J. R.; NEARING, M. A. Humanization of Decision Support Using Information from Simulations. In: PEART, R.M. e CURRY, R. B. (Ed). Modeling Agricultural Systems , Marcel Dekker, Gainsville, Florida, 1998, 1-18.

BELLOTI, W. D. The role of forages in sustainable cropping systems of Southern Australia. In: INTERNATIONAL GRASSLAND CONGRESS, 19, Piracicaba, 2001. Proceedings. Piracicaba : FEALQ, 2001.p. 729-735.

BERCHIELLI, T.T.; SOARES, J.P.G.; AROEIRA, L.J.M.; FURLAN, C.L.; SALMAN, A.K.D.; SILVEIRA, R.N. de; MALHEIROS, E.B. Estimativa da ingestão voluntária a partir das características de degradação do capim Coastcross(Cynodon dactylon L. Pers.), sob pastejo, por vacas em lactação. Revista Brasileira de Zootecnia, v.30, n.4, p. 1332-1339, 2001.

BONHOMME, R. Bases and limits to using 'degree-day'units. European Journal of Agronomy. v. 13, p. 1-10, 2000. 
BRAGA, G. J. Resposta do capim-Mombaça (Panicum maximum Jacq.) a doses de nitrogênio e intervalos de corte. Pirassununga, 2001. 121p. Dissertação (Mestrado) - Faculdade de Zootecnia e Engenharia de Alimentos - Universidade de São Paulo.

BUDNICK, F. S. Applied Mathematics for Business, Economics, and The social Sciences. New York, McGraw Hill,1990. 206p.

CACHO, O. J. A pratical equation for pasture growth under grazing. Grass and Forage Science. v. 48, p. 387-394. 1993.

CAIXETA FILHO, J. V. Pesquisa Operacional: Técnicas de Otimização Aplicadas a Sistemas Agroindustriais. Piracicaba : ED. J. V. CAIXETA FILHO, 2000. 212 p.

CANGIANO, C. Com past 3.0 - programa de computação para estimar o consumo de bovinos em pastejo: uma aplicação em sistemas leiteiros. In: EVERLING, D. M.; QUADROS, F. L. F. de; VIÉGAS, J.; SANCHES, L. M. B.; GONÇALVES, M. B. F.; LOVATTO, P. A.; RORATO, P. R. N. (Ed.) Modelos para a tomada de decisões na produção de bovinos e ovinos, Santa Maria, 2002. Anais. Santa Maria:UFSM, 2002. p. 69-94.

CARNEVALLI, R. A. Desempenho de ovinos e respostas de pastagens de Cynodon spp submetidos a regimes de desfolha sob lotação contínua. Piracicaba, 1999. 90p. Dissertação (Mestrado) - Escola Superior de Agricultura "Luiz de Queiroz" , Universidade de São Paulo.

CEZAR, I. M. Modelo bioeconômico de produção de bovinos de corte 1. Descrição do modelo. Pesquisa Agropecuária Brasileira, v. 17, n.6, p. 941-949, 1982 a. 
CEZAR, I. M. Modelo bioeconômico de produção de bovinos de corte 1l. Avaliação econômica na pastagem cultivada em um sistema extensivo de cria no Brasil central. Pesquisa Agropecuária Brasileira, v. 17, n.7, p. 1093-1107, 1982 b.

CHACON, E.; STTOBS, T. H. Influence of progressive defoliation of grass sward on the eating behavior of cattle. Australian Journal of Agricultural Research, v. 27, p.709-727, 1975.

Da SILVA, S. C.; PEDREIRA, C. G. S. Princípios de ecologia aplicados ao manejo da pastagem. In: FAVORETTO, V.; RODRIGUES, L. R. de A.; RODRIQUES, T. de J. D. (Ed.) ECOSSISTEMA DE PASTAGEM, 3., Jaboticabal, 1996. Anais. Jaboticabal:UNESP, 1996. p. 01-62

Da SILVA, S. C.; SBRISSIA, A. F. A planta forrageira no sistema de produção animal. In: SIMPÓSIO SOBRE MANEJO DE PASTAGENS, 17., Piracicaba, 2000. Anais. Piracicaba: FEALQ, 2000. p. 03-20.

DEMMENT, M. W.; PEYRAUD, J. L.; LACA, E. A. Herbage intake at grazing: a modeling approach. In: JOURNET, M.; GRENET, E.; THERIEZ, M. (Eds.) Recent developments in the nutrition of herbivores.In: INTERNATIONAL SYMPOSIUM ON THE NUTRITION OF HERBIVORES, 4., Proceedings. Paris:INRA editions, 1995. p. 121-141.

DIAS, C. T. dos S. PLANEJAMENTO DE UMA FAZENDA EM CONDIÇÕES DE RISCO: PROGRAMAÇÃO LINEAR E SIMULAÇÃO MULTIDIMENSIONAL. . Piracicaba, 1996. 100p. Tese (Doutorado) - Escola Superior de Agricultura "Luiz de Queiroz", Universidade de São Paulo. 
DOURADO NETO, D.; TERUEL, D. A.; REICHARDT, K; NIELSEN, D. R.; FRIZZONE, J. A.; BACCHI, O. O. S. Principles of crop modeling and simulation: 1. Uses of mathematical models in model development. Scientia Agricola, v. 55 n.esp, p. 46-50, ago, 1998a.

DOURADO NETO, D.; TERUEL, D. A.; REICHARDT, K; NIELSEN, D. R.; FRIZZONE, J. A.; BACCHI, O. O. S. Principles of crop modeling and simulation: 11. The implications of the objective in model development. Scientia Agricola, 55 n. esp., p. 51-57, ago, 1998b.

DOURADO NETO, D.; TERUEL, D. A.; REICHARDT, K; NIELSEN, D. R.; FRIZZONE, J. A.; BACCHI, O. O. S. Principles of crop modeling and simulation: 11l. Modeling of root growth and other belowground processes, limitations of the models, and the future of modeling in agriculture. Scientia Agricola, 55 n. esp., p.58-61, ago., 1998c.

DÙRÚ, M. Modelando o sistema de produção leiteira em pastagens. In: EVERLING, D. M.; QUADROS, F. L. F. de; VIÉGAS, J.; SANCHES, L. M. B.; GONÇALVES, M. B. F.; LOVATTO, P. A.; RORATO, P. R. N. (Ed.) Modelos para a tomada de decisões na produção de bovinos e ovinos, Santa Maria, 2002. Anais. Santa Maria:UFSM, 2002. p. 37-68.

DURU, M.; DUDROCQ, H.; FABRE, C.; FEUILLERAC, E. Modeling net herbage accumulation of an orchardgrass sward. Agronomy Journal. v.94, p. 1244-1256. 2002. 
EUCLIDES, V.B.P.; THIAGO, L.R.L.S.; MACEDO, M.C.M.;OLIVEIRA, M.P. Estimativas de consumo voluntário de forragem de três cultivares de Panicum maximum sob pastejo. Revista Brasileira de Zootecnia, v. 28, n. 6 p. 1177-1185, 1999.

FAGUNDES, J. L. Efeito de intensidades de pastejo sobre o índice de área foliar, interceptação luminosa e acúmulo de forragem em pastagens de Cynodon spp. Piracicaba, 1999. 69p. Dissertação (Mestrado) - Escola Superior de Agricultura “Luiz de Queiroz", Universidade de São Paulo.

FIALHO, F.B. Sistemas de apoio à decisão na produção de suínos e aves. In: REUNIÃO ANUAL DA SOCIEDADE BRASILEIRA DE ZOOTECNIA, 36, Porto Alegre, 1999. ANAIS. Porto Alegre : SBZ, 1999.p. 307-317.

FIALHO,F.B.; LEDUR, M.C. Segmented polynomial model for estimation of egg production curves in laying hens. British Poultry Science, v.38, n.1, p. 66-73, 1997.

FREER, M.; MOORE, A. D.; DONNELlY, J. R. GRAZPLAN: Decision Support Systems for Australian Grazing Enterprises--II. The Animal Biology Model for Feed Intake, Production and Reproduction and the GrazFeed DSS, Agricultural Systems, v. 54, n. 1, p. 77-126, 1997.

GOMIDE C. C. C. Algumas características fisiológicas e químicas de cinco cultivares de Cynodon. Jaboticabal, 1996. 100p. Dissertação (Mestrado) - Faculdade de Ciências Agrária e Veterinárias, Universidade Estadual Paulista "Júlio de Mesquita Filho". 
GOMIDE, J.A.; WENDLING, I.J.; BRÁS, S.P.; QUADROS, H.B. Consumo e produção de leite de vacas mestiças em pastagem de Brachiaria decumbens manejada sob duas ofertas diárias de forragem. Revista Brasileira de Zootecnia, n.30, v. 4, p.1194-1199, 2001.

GORDON, I. J.; LASCANO, C. Foraging strategies of ruminant livestock on intensively managed grasslands: potential and constraints.In: International Grassland Congress.Local, 1993 Proceedings:Local Palmerston North, 1993 New Zealand Grassland Association, 1993. p. 681-690.

HODGES, T. Temperature and water stress effects on phenology. In:Predicting crop phenology. Boca Raton, Florida:CRC Press:1990, p. 7-13.

HODGSON, J. Grazing management: Science in to practice. New York:Longman Handbooks in Agriculture, 1990. 230p.

HOLMES, C. W. Produção de leite a baixo custo em pastagem: análise do sistema neozelandês. In: CONGRESSO BRASILEIRO DE GADO LEITEIRO, 2., Piracicaba, 1995. Conceitos Modernos de Exploração Leiteira. Anais. Piracicaba:FEALQ, 1996. p. 69-96.

KVALSET, T. O. Cautionary note about $R^{2}$. American Statistician, v. 39., n4., p.279285. 1985

LEMOS FILHO, J. P.; VILlA NOVA, N. A.; PINTO, H. S. A model including phoperiod in degree-days for estimating Hevea bud growth. International Journal of Biometeorology. v.41, p. 1-4, 1997. 
LOVATTO, P. A. Premissas básicas para o desenvolvimento de modelos na agricultura. . In: EVERLING, D. M.; QUADROS, F. L. F. de; VIÉGAS, J.; SANCHES, L. M. B.; GONÇALVES, M. B. F.; LOVATTO, P. A.; RORATO, P. R. N. (Ed.) Modelos para a tomada de decisões na produção de bovinos e ovinos, Santa Maria, 2002. Anais. Santa Maria:UFSM, 2002. p. 09-36.

LUDLOW, M. M. Light relations of pastures plants. In: Plant relation in pastures. WILSON, J. R. (Ed.). East Melbourne, Australia:CSIRO, 1978, p.35-49.

MARASCHIN, G. E. Relembrando o passando, entendendo o presente e planejando o futuro: uma herança em forrageiras e um legado em pastagens. In: REUNIÃO ANUAL DA SOCIEDADE BRASILEIRA DE ZOOTECNIA, 37., Viçosa, 2000. Anais. Viçosa:SBZ, p 113-179, 2000

MARSHALL, P. R.; McCALL, D. G.; JOHNS, K. L. Stockpol: a decision support model for livestock farms. Proceedings of the New Zealand Grassland Association, v. 53, p. 137-140. 1991.

McCALL, D. G. A systems approach to research planning for north island hill country. . Palmerston North, 1984, Thesis (PhD) - Massey University. 261p.

McCALL, D. G.; TITHER, P. M. Use of the Stockpol: computer decision-support model program in commercial consultancy. Proceedings of the New Zealand Grassland Association, v. 55, p. 207-208. 1993.

McCALL, D. G.; BISHOP-HURLEY, G.J. A pasture growth model for use in a wholefarm dairy production model. Agricultural Systems, v. 76, p. 1183-1205, 2003. 
MCCOWN, R.I.; CARBERRY, P.S.; FOALE, M.A.; HOCHMAN, Z.; COUTTS J.A.;

DALGLIESH, M.P. The farmscape approach to farming systems research. AUSTRALIAN AGRONOMY CONFERENCE, 9., Proceedings, 1998, p. 633-636.

McWILLIAM, J. R. Response of pastures plants to temperature. In: WILSON, J. R.

(Ed.) Plant Relation in Pastures., East Melbourne, Australia:CSIRO, 1978. p.1734.

MEDEIROS, H. R. de; PEDREIRA, C. G. S. ; VILLA NOVA, N. A. Temperatura base de gramíneas determinada utilizando o conceito de unidade fototérmica. In: (Compact disc) REUNIÃO ANUAL DA SOCIEDADE BRASILEIRA DE ZOOTECNIA, 39., Recife, 2002. Anais. Recife:SBZ, 2002.

MEDEIROS, H. R. de; PEDREIRA, C. G. S. ; VILLA NOVA, N. A. ; BARIONI, L. G.; MELLO, A. C. L. Prediction of herbage accumulation of Cynodon Grasses by an empirical model based on temperature and daylength. In: INTERNATIONAL GRASSLAND CONGRESS, 19, Piracicaba, 2001,. Proceedings. Piracicaba:FEALQ, 2001. p. 263-265.

NABINGER, C. Princípios da exploração intensiva de pastagens. In: SIMPÓSIO SOBRE MANEJO DE PASTAGENS, 14., Piracicaba, 1997. Anais. Piracicaba: FEALQ, 1997. p. 213-251.

NELSON, B. L. Stochastic Modeling: Analysis and Simulation. McGraw-Hill, 1995. $321 \mathrm{p}$.

NEWMAN, J. A.; PARSONS, A. J.; THORNLEY, J. H. M.; PENNING, P. D.; KREBS, J. R. Optimal diet selection by a generalist grazing herbivore. Functional Ecology, v.9, n. 2, p. 255-268, 1995. 
ORSKOV, E . R.; McDONALD, I. The estimation of protein degradability in the rumen from incubation measurements weighted according to rate of passage. Journal Agricultural Science, v. 92, p. 499-503, 1979.

PARSONS, A.J.; LEAFE, E. L. ; COLLET, B. STILES, W The physiology of grass production under grazing. II. Photosynthesis, crop growth and animal intake of continuously grazed swards. Journal of Applied Ecology, v.20, p.127-139. 1983.

PARSONS, A. J.; THORNLEY, J. H. M.; NEWMAN, J.; PENNING, P. D. A mechanistic model of some physical determinants of intake rate and diet selection in a two-species temperate grassland sward. Functional Ecology, v. 8, p. 187-204. 1994

PASSIOURA, J. B. Simulation models: science, snake oil, education, or engineering. Madison: Agronomy Journal, v.88, p. 690-694, 1996.

PEDREIRA, C. G. S. Avanços metodológicos na avaliação de pastagens. In: REUNIÃO ANUAL DA SOCIEDADE BRASILEIRA DE ZOOTECNIA, 39., Recife, 2002. Anais. Recife:SBZ, 2002. p 10-150.

PINTO, L. F. de M. Dinâmica do acúmulo de matéria seca em pastagens de Cynodon spp. submetidas a pastejo. Piracicaba, 2000. 124p. Dissertação (Mestrado) - Escola Superior de Agricultura “Luiz de Queiroz”, Universidade de São Paulo.

RAGSDALE, C. T. Spreadsheet modeling and decision analysis: a pratical introduction to management science., Cincinnati, Ohio:SouthWestern College Publishing, 1997. 730 p. 
RODRIGUES, T. de J. D.; RODRIGUES, L. R. de A.; REIS, R. de A. Adaptação de plantas forrageiras as condições adversas. In: FAVORETTO, V.; RODRIGUES, L. R. A.; REIS, R. de A. (Ed.). SIMPÓSIO SOBRE ECOSSISTEMAS DE PASTAGENS 2, Jaboticabal, 1989. Anais. Jaboticabal:FUNEP,UNESP, 1989. P1761.

ROLIM, F. A. Estacionalidade de produção forrageira. In: SIMPÓSIO SOBRE MANEJO DE PASTAGENS, 6., Piracicaba, 1980, Moura, J. C.; Faria, V. P. de (Ed.). 1980, Piracicaba:ESALQ, 1980. p. 39-81.

SANTOS, P. M. Estudo de algumas características agronômicas agronômicas de Panicum maximum (Jacq.) cvs. Tanzânia e Mombaça para estabelecer seu manejo. Piracicaba, 1997. 62p. Dissertação (Mestrado) - Escola Superior de Agricultura "Luiz de Queiroz", Universidade de São Paulo.

SAS INSTITUTE, SAS User's guide: Release 6.03 ed. Cary, 1988. 1028p.

SOLLENBERGER, L. E.; MOORE, J.E. Assessing forage allowance - animal performance relationships on grazed pasture. Agronomy Journal. V. 89, p. 140141,1997

STANDING COMMITTEE ON AGRICULTURE RUMINANTS - SCA Feeding standards for Australian livestock. Ruminants. Australia:CSIRO, 1990. 266 p.

SOWELL, R. S.; WARD, R. C. Modeling Processes and Operations with Linear Programming. In: PEART, R.M. e CURRY, R. B. (Ed.) Modeling Agricultural Systems., Gainsville, Florida:Marcel Dekker, 1998. Gainsville, 1990. P. 113-156.

SQUIRE, G. R. The physiology of tropical crop production. CAB International. 236p. 1990 
STARFIELD, M.; SMITH, K. A.; BLELOCH, A. L. How to model it: problem solving for the computer age. McGraw Hill, New York, 1990. 206p.

STOBBS, T. H. The effect of plant structure on the intake of tropical pastures. Variation in the bite size of grazing cattle. Australian Journal of Agricultural Research v.24, p. 809-819, 1973a.

STOBBS, T. H. The effect of plant structure on the intake of tropical pastures. Differences in sward structures, nutritive value, and bite size of animals grazing Setaria anceps and Chloris gayana at various stages of growth. Australian Journal of Agricultural Research. v. 24, p. 821-829, 1973 b.

STOBBS, T. H. Factors limiting the nutritional value of grazed tropical pastures for beef and milk production. Tropical Grasslands. v. 9, n. 2, p. 141-149, 1975.

STOCKPOL User manual., Hamilton, Nova Zelândia:AgResearch (Ed.), 1996.145p.

TATIZANA, S. A. Um modelo conceitual de simulação da produção de gado de corte. Piracicaba:ESALQ, 1995, 95p. Dissertação (Mestrado) - Escola Superior de Agricultura “Luiz de Queiroz”, Universidade de São Paulo.

THE FORAGE AND GRASSLAND TERMINOLOGY COMMITTEE - FGTC Terminology for grazing lands and grazing animals. Journal of Production Agriculture, v.5, p.191-201, 1992.

TONATO, F.; MORENO, L.S. de B.; PEDREIRA, C. G. S.; MEDEIROS, H. R. de Produção de matéria seca total e taxa média de acúmulo de forragem de cinco cultivares do gênero Cynodon manejados para a produção de feno sob irrigação. In: (Compact disc) REUNIÃO ANUAL DA SOCIEDADE BRASILEIRA DE ZOOTECNIA, 39., Recife, 2002. Anais. Recife:SBZ, 2002. CD-ROM. 
THORNLEY, J. H. M. Modeling grassland ecosystems. In: INTERNATIONAL GRASSLAND CONGRESS, 19., Piracicaba 2001, Anais. Piracicaba:FEALQ, 2001. p. 1029-1036.

THORNLEY, J. H. M. ; JOHNSON, I. R. plant and crop modeling: A mathematical approach to plant and crop physiology. Oxford:Clarendon Press. 1990. 491p.

THORNLEY, J. H. M.; PARSONS, A. J.; NEWMAN, J.; PENNING, P. D. A costbenefit model of grazing intake and diet selection in a two-species temperate grassland sward. Functional Ecology, v. 8, p. 5-16. 1994

UNGAR, E. D.; NOY-MEIER, I. Herbage intake in relation to availability and sward structure: grazing processes and optimal foraging. Journal of Applied Ecology, v. 25, p. $1045-1062,1988$

VILLA NOVA, N.A.; CARRETEIRO, M.V.; SCARDUA, R. Um modelo para avaliação do crescimento de cana-de-açúcar (Sacharum spp.) em termos da ação combinada do fotoperíodo e da temperatura média do ar. In: CONGRESSO BRASILEIRO DE AGROMETEOROLOGIA, 2., Campinas, 1983, Anais. Sociedade Brasileira de Agrometeorologia/Instituto Agronômico de Campinas: Sociedade Brasileira de Agrometeorologia/Instituto Agronômico de Campinas, 1983. p.31-48.

VILLA NOVA, N.A.; BARIONI, L.G.; PEDREIRA, C.G.S.; PEREIRA, A.R. Modelo para previsão da produtividade do capim elefante em função da temperatura do ar, fotoperíodo e frequiência de desfolha. Revista Brasileira de Agrometeorologia, v. 7, p. 75-79, 1999. 
WEBBY, R. W.; McCALL, D. G.;BLANCHARD, V. J. An evaluation of the Stockpol $^{\mathrm{TM}}$ model. New Zealand Society of Animal Production. v. 55, p. 145-149, 1995.

WONES, J. W.; LUYTEN, J. C. Simulation of Biological Processes. In: PEART, R.M.

e CURRY, R. B. (Ed.) Modeling Agricultural Systems., Gainsville, Florida:Marcel Dekker, 1998. p. 19-62.

WOODWARD, S. J. R. Formulae for predicting animal's daily intake of pasture and grazing time from bite weight and composition. Livestock Production Science, v. 52, p. 1-10, 1997.

WOODWARD, S.J.R.; WEBBY, R.W.; JOHNSTONE, L.J.C. A decision tool for calculating herbage mass and metabolisable energy requirements of growing cattle and sheep. Proceedings of the New Zealand Grassland Association, v. 62, 13-18, 2000.

WOODWARD, S. J. R.; WAKE, G. C.; PlEASANTS, A. B.; MACALL, D. G. A. Simple model for optimizing rotational grazing. Agricultural Systems, v. 41, p. 123-155, 1993.

WOODWARD, S.J.R.; LAMBERT, M.G.; LITHERLAND, A.J.; BOOM, C.J. Can a mathematical model accurately predict intake of grazing animals? Testing the QGraze model. New Zealand Society of Animal Production, v.61, p. 4-7, 2001.

YIN, X.; KROPFF, M. J.; McLAREN, G.; VISPERAS, R.M. A nonlinear model for crop development as a function of temperature. Agricultural and Forest Meteorology. v.77, p.1-16, 1995. 